\title{
ELASTIC CONSTANTS OF ARTIFICIAL AND NATURAL ICE SAMPLES BY BRILLOUIN SPECTROSCOPY
}

\author{
By P. H. Gammon*, H. Kiefte, M. J. Clouter, and W. W. Denner $\dagger$ \\ (Department of Physics, Memorial University of Newfoundland, St John's, \\ Newfoundland A1B 3X7, Canada)
}

\begin{abstract}
The method of Brillouin spectroscopy has been used to measure the dynamic elastic moduli of local homogeneous regions in ice samples representing four different environments of formation. These included artificial ice frozen from distilled water, clear monocrystalline glacial ice, bubbly lake ice, and sea ice. The samples studied were found to have identical local elastic properties. Accordingly the elastic properties of homogeneous monocrystalline ice have been found not to vary with sample age, with impurities present at the time of freezing, or with crystal quality. The bulk elastic properties of ice remain, of course, subject to modification by different crystal grain textures and the presence of inclusions of various sorts. Because the elastic constants obtained in the present work are subject to smaller overall uncertainty than values measured previously, it is believed that they are the most reliable obtained to date. The values at $-16^{\circ} \mathrm{C}$ were determined to be $c_{11}=139.29 \pm 0.41$, $c_{12}=70.82 \pm 0.39, c_{13}=57.65 \pm 0.23, c_{33}=150.10 \pm 0.46, c_{44}=30.14 \pm 0.11$ (units of $10^{8} \mathrm{~N} \mathrm{~m}^{-2}$ or kbar). A full range of derived elastic parameters for monocrystalline ice and for homogeneous isotropic polycrystalline ice has been calculated.
\end{abstract}

RÉSUMÉ. Constantes élastiques d'echantillons de glace artificielle et naturelle par spectrographie de Brillouin. On a utilisé la méthode de la spectrographie de Brillouin pour mesurer les modules dynamiques élastiques de régions localement homogènes dans des échantillons de glace représentant quatre différentes circonstances de formation. Il s'agissait d'une glace artificielle obtenue à partir d'eau distillée, d'une glace claire monocristalline, d'une glace bulleuse de lac et d'une glace de mer. On a trouvé que les échantillons étudiés avaient des propriétés élastiques locales identiques. Logiquement, les propriètés élastiques d'une glace homogène monocristalline ont été trouvées indépendantes de l'âge de l'échantillon, des impuretés présentes au moment de la congélation ou de la qualité du cristal. Les propriétés élastiques globales de la glace demeurent, naturellement, sujettes à modifications selon les différentes textures cristallines des grains et la présence d'inclusion de différentes sortes. Comme les constantes élastiques obtenues dans la présente étude sont affectées d'une incertitude globale inférieure aux valeurs précédemment mesurées on pense qu'elles sont les plus dignes de confiance obtenues jusqu'ici. Les valeurs obtenues à $-16^{\circ} \mathrm{C}$ ont été: $c_{11}=139,29 \pm 0,41, c_{12}=70,82 \pm 0,39, c_{13}=57,65 \pm 0,23, c_{33}=150,10 \pm 0,46$, $c_{44}=30,14 \pm 0,11$ (unités: $10^{8} \mathrm{~N} \mathrm{~m}^{-2}$ ou kbars). Toute une série de paramètres élastiques dérivés ont été calculés pour de la glace monocristalline et pour une glace polycristalline homogène et isotrope.

ZuSAMMENFASSUNG. Elastiche Konstanten von künstlichen und natürlichen Eisproben, gewonnen mit Brillouin-spektroskopie. Das Verfahren der Brillouin-Spektroskopie wurde zur Messung der dynamischen elastischen Moduln lokaler homogener Bereiche in Eisproben, die vier verschiedene Bildungsverhältnisse umfassen, herangezogen. Dazu gehörte künstliches Eis aus destilliertem Wasser, klares monokristallines Gletschereis, blasenreiches Seeeis und Meereis. Die lokalen elastischen Eigenschaften der untersuchten Proben erwiesen sich als identisch. Entsprechend zeigt sich, dass die elastischen Eigenschaften von homogenem monokristallinem Eis sich mit dem Alter der Probe, mit den im Gefrierzeitpunkt vorhandenen Verunreinigungen oder mit der Qualität der Kristalle nicht ändern. Die mittleren elastischen Eigenschaften des Eises unterliegen natürlich Änderungen durch verschiedene Kristallkorngefüge und infolge der Anwesenheit von Einschlüssen verschiedener Art. Da die in der vorliegenden Arbeit gewonnenen elastischen Konstanten in ihrer Gasamtheit genauer sind als früher gemessene Werte, werden sie als die derzeit zuverlässigsten betrachtet. Die Werte bei $-16^{\circ} \mathrm{C}$ ergaben sich zu $c_{11}=139,29 \pm 0,41, \quad c_{12}=70,82 \pm 0,39, \quad c_{13}=57,65 \pm 0,23, \quad c_{33}=150,10 \pm 0,46$, $c_{44}=30,14 \pm 0,11$ (Dimension $10^{8} \mathrm{~N} \mathrm{~m}^{-2}$ oder kbar). Eine vollständige Reihe abgeleiteter elastischer Parameter für monokristallines Eis und für homogenes isotropes polykristallines Eis wurde berechnet.

* Present address: Ice Engineering Ltd., P. O. Box 6082, St John's Newfoundland A1C 5X8, Canada

$\dagger$ Present address: Science Applications Inc., 2999 Monterey-Salinas Hwy, Monterey, California 93940, U.S.A. 


\section{INTRODUCTION}

The mechanical properties of naturally occurring ice are complex and varied. In large measure the complexity stems from the usual proximity of ice to its melting temperature, while the variability reflects the wide range of modes of occurrence of ice in the natural environment. Accordingly, investigations of the quantitative rheology of natural ice necessitate particular caution both in experimental design and in the interpretation of results.

The elastic properties of ice represent the simplest aspect of ice rheology and have been comparatively well studied. Nevertheless, discrepancies in sets of results quoted by various investigators sometimes lie outside probable experimental uncertainty. It is not always clear whether such discrepancies are due to variations in experimental technique or to real differences in the elastic properties of different ice samples. Only by applying a single technique to samples representing differing modes of formation can sample-to-sample variations be definitively assessed.

The present investigation specifically addresses the latter point. The work represents the first application of a single measurement technique to determine the dynamic elastic moduli (i.e. the elastic stiffness constants) in local homogeneous regions of ice samples representing four different environments of formation. These included artifical ice frozen from distilled water (Gammon and others, 1980), glacial ice, bubbly lake ice, and sea ice.

\section{Review of previous work}

The hexagonal phase of ice, found in the natural environment and designated ice Ih, is only one of a large number of polymorphs of solid $\mathrm{H}_{2} \mathrm{O}$ (Whalley, 1969; Fletcher, 1970; Hobbs, 1974; Glen, 1974). Ice Ih is presumed to belong to the space group $\mathrm{P} 6_{3} / \mathrm{mmc}$. The elastic behaviour is therefore concisely described by a set of five elastic moduli (Nye, 1957; Landau and Lifshits, 1959; Musgrave, 1970), the determination of which has been the subject of a series of previous investigations.

Work on elastic properties of ice up until 1940 is reviewed in a text by Dorsey (1940). Most measurements were made using static techniques applied to polycrystalline samples. A few dynamic (sound velocity) measurements were carried out using polycrystalline samples, but the results were quite imprecise.

In 1948 Penny (1948) reported a quasi-theoretical determination of the elastic moduli of monocrystalline ice. Penny assumed (i) that the oxygen atoms were in perfect tetrahedral coordination, (ii) that the hydrogen atoms were located at the midpoints of nearest-neighbour $\mathrm{O}-\mathrm{O}$ bonds, and (iii) that only nearest-neighbour interactions need be included in the dynamical model. The analysis, which was based on the usual theory of lattice dynamics, led to expressions for the five elastic moduli of ice in terms of two atomic force constants. These force constants were, in turn, fitted to Northwood's (1947) acoustic measurements of Young's modulus and Poisson's ratio for polycrystalline ice, and the values were linked to the monocrystalline elastic moduli via the averaging procedure of Voigt (1910).

The first experimental determination of the full set of elastic moduli of monocrystalline ice was reported by Jona and Scherrer (1952). The samples employed were artificially formed monocrystals of ice at $-16^{\circ} \mathrm{C}$. The application of the Schaefer-Bergmann technique yielded reasonably precise values for all five elastic moduli and the results were used to test the three theoretical relations of Penny (1948). Agreement was within experimental uncertainty.

In 1956 Green and Mackinnon (1956) measured the transit times of compressional and shear 
acoustic pulses along the $c$-axis of monocrystalline ice samples. These measurements yielded values for $c_{33}$ and $c_{44}$ which were in turn used to calculate the other three elastic moduli by way of Penny's relations. Agreement with the values of Jona and Scherrer (1952) was approximately within experimental uncertainty.

A measurement of the complete set of elastic compliance constants of artificial monocrystalline ice was reported by Bass and others (1957). However, for purposes of comparison with other measurements, the elastic compliance matrix must be inverted to obtain the elastic stiffness-constant matrix (i.e. the elastic moduli) and this significantly increases the uncertainty in the results.

The first measurement of the full set of elastic moduli for monocrystalline natural ice was reported by Bogorodskiy (1964). The samples consisted of large clear monocrystals extracted from bulk ice samples from Lake Ladoga in the U.S.S.R. The elastic moduli were determined from measurements of acoustic pulse transit times in three crystallographic directions. However, the relatively large uncertainty of $10 \%$ in the elastic moduli, precludes detailed comparison with more precise measurements on artificial ice samples.

The elastic moduli of artificial ice at temperatures ranging from $-20^{\circ} \mathrm{C}$ to very near the melting point were measured by Brockamp and Querfurth ([1965]). An ultrasonic pulse method was used and the resulting values were in fairly good agreement with those of Jona and Scherrer (1952). Also at this time, the temperature dependence of two of the elastic moduli of ice, $c_{11}$ and $c_{33}$, was investigated by Zarembovitch and Kahane (1964) using the Schaefer-Bergmann method. The agreement between their measurements at $-16^{\circ} \mathrm{C}$ and those of Jona and Scherrer (1952) was excellent.

The first comprehensive investigation of the elastic moduli of ice at low temperatures was reported by Proctor (1966). Monocrystalline samples frozen from distilled water were tested over a temperature range from $-223^{\circ} \mathrm{C}$ to $-23^{\circ} \mathrm{C}$. The complete set of elastic moduli was determined over the range from $-213^{\circ} \mathrm{C}$ to $-163^{\circ} \mathrm{C}$ using an ultrasonic method. The resulting elastic modulus data were fitted with a quadratic least-squares temperature-dependence curve.

In 1967 Dantl (1968, 1969, unpublished) reported measurements of the elastic moduli of ice over the broad temperature range $-140^{\circ} \mathrm{C}$ to $-0.7^{\circ} \mathrm{C}$. Frequency dependence over the range from $5 \mathrm{MHz}$ to $140 \mathrm{MHz}$ was also investigated. Particular caution was exercised in forming the monocrystalline ice samples utilized in these measurements. They were grown slowly from water prepared in a quartz multiple-distillation apparatus. Following freezing, the monocrystalline ice samples were aged for at least eight months at a temperature near the melting point before being used in the acoustic experiments. The elastic moduli of the ice samples were measured by Dantl using a combination of two acoustic techniques. He used the conventional pulse-echo technique to obtain precise relative measurements of the elastic moduli, including temperature and frequency dependence, while he used the double-pulse interference method to check the absolute values of the velocities. The measurements were interpreted to yield least-squares quadratic temperature-dependence curves for the elastic moduli of ice over the range $-140^{\circ} \mathrm{C}$ to $0{ }^{\circ} \mathrm{C}$. The curves revealed a very gradually decelerating increase in the moduli with decreasing temperature. The slope of the curves in the neighbourhood of the melting point was of the order of 1.5 parts per thousand per ${ }^{\circ} \mathrm{C}$. No significant frequency dependence of the elastic moduli of ice was noted by Dantl.

The most notable observation which stems from the comprehensive set of measurements carried out by Dantl relates to the absolute or systematic values obtained. The elastic constants averaged about $5 \%$ below the values obtained by other previous authors, in particular Jona and 
Scherrer (1952), and the discrepancy could not be accounted for by the estimated experimental uncertainty in the respective sets of results. A similar inconsistency with Dantl's measurements was noted as a result of recent work by the present authors (Gammon and others, 1980).

Dantl (1968, 1969, unpublished) attributed his apparently low elastic moduli to a fundamental difference in elastic properties of aged pure ice samples (used in his work) versus the unaged samples used by other authors. Dantl offers a tentative explanation for this in terms of preferential $\mathrm{H}_{2} \mathrm{O}$ dipole orientation during time of freezing, this, in effect, tending to pull the crystal structure slightly together and hence yield increased elastic moduli. He then argues that during ageing at or near the melting point the dipoles reassume random orientations so that the density and elastic moduli thereby decrease with age. Dantl substantiates his arguments by pointing out a tendency for ice of minimum age to have maximum density (Dantl and Gregora, 1968). This however, is not borne out by the precise density measurements of Ginnings and Corruccini (1947), Butkovich (1955), and Camp (1978) (who attempted to measure volume changes of a freshly formed ice sample held for 60 days at $-4{ }^{\circ} \mathrm{C}$ and essentially obtained a null result). Dantl's polar structure hypothesis is also not consistent with neutron crystallographic data (Kamb, 1973), tests for piezoelectricity in ice (Teichmann and Schmidt, 1965), and determinations of the zero-point entropy of ice which are in excellent agreement with a theoretical value based on assumed disorder in the proton arrangement (Fletcher, 1970; Hobbs, 1974).

It can nevertheless be noted that the measurements of Dantl, when compared to those of other authors, do imply a sample-to-sample variation in the elastic moduli of ice. However, the explanation put forth by Dantl seems improbable in the light of existing data. It may thus be advisable to look for some other explanation, such as differences in impurity concentration or in crystal quality or, alternatively, unnoticed systematic error in sets of measurements made in different laboratories using different techniques.

\section{Brillouin spectroscopy}

In a previous publication (Gammon and others, 1980) it was demonstrated that Brillouin spectroscopy is an effective technique for accurately measuring the fundamental local elastic properties of artificially formed ice monocrystals. From the present work it is clear that this is also the case for natural ice samples, notwithstanding their heterogeneous composition and the fact that they may contain inclusions of material other than ice, such as air, water vapour (air bubbles, internal cracks, etc.), or liquid water (Tyndall figures, brine cells, brine channels, etc.). In fact Brillouin spectroscopy can be used to probe the elastic properties of small regions (as small as $0.2 \mathrm{~mm}$ ) in such samples, and this has been clearly demonstrated by the present authors in studying the local acoustic properties of a natural ice sample near a crystal grain boundary (Gammon and others, 1981[a]).

The technique of Brillouin spectroscopy involves the scattering of light from hypersonic (acoustic) waves which are thermally induced and hence arise spontaneously within a sample. The incident light is effectively Doppler-shifted upon scattering from these propagating density fluctuations. This permits accurate spectroscopic measurement of hypersonic velocities by means of the Brillouin equation:

$$
V=\Omega \lambda /(2 n \sin \alpha / 2)
$$

where $V$ denotes sound velocity, $\Omega$ Brillouin frequency shift, $\lambda$ wavelength of incident (laser) light, $n$ refractive index of a transparent medium, and $\alpha$ scattering angle. 
The equations linking acoustic propagation velocities to the density and elastic moduli of a solid medium are derived via Hooke's law. This yields, in the general case, three independent acoustic modes or frequency-shifted components; one is predominantly longitudinal (L) and two predominantly transverse $\left(\mathrm{T}_{1}\right.$ and $\mathrm{T}_{2}$ ), (Landau and Lifshits, 1959; Benedek and Fritsch, 1966; Stoicheff, 1973, 1977). Measurement of $L, T_{1}$, and $T_{2}$ in different crystal orientations in turn leads to accurate determination of the elastic moduli.

In summary, the most relevant characteristics and advantages of the Brillouin scattering technique are, (i) the inherently good precision of measurement, (ii) the relative simplicity of identification and evaluation of systematic errors, and (iii) the regions of observation are highly localized. In view of the principal objective of this work, the technique is therefore particularly appropriate since it can be applied uniformly to a variety of different samples with the capability of detecting small variations in the elastic moduli from sample to sample

\section{EXPERIMENTAL TECHNIQUE}

The most commonly used arrangement for observing Brillouin scattering in transparent media involves a highly monchromatic laser light source, incident on a sample at an angle $\alpha$ (usually of $90^{\circ}$ ) with the precisely defined axis of an optical dispersion and detection system (Durand and Pine, 1968; Sandercock, 1975; Stoicheff 1973; 1977). Because the frequency shifts yielded by the Brillouin equation are typically a very small fraction $\left(c \cdot 10^{-5}\right.$ to $\left.10^{-6}\right)$ of the frequency of the incident radiation, an accurate analysis of the Brillouin spectra requires an instrument capable of very high resolution. Likewise the low intensity of Brillouin scattering necessitates a sophisticated optical detection and data-acquisition system.

In the present experiments the incident light source was a single-mode argon-ion laser (Spectra Physics 165-08) operating at a power output of about $100 \mathrm{~mW}$ and a wavelength of $514.5 \mathrm{~nm}$. The scattered light was analyzed by using a piezoelectrically scanned, triple-pass Fabry-Perot interferometer (Burleigh Instruments RC110) with a free spectral range of $11.101 \mathrm{GHz}$. A cooled photomultiplier detector (ITT FW 130) was coupled to the multichannel analyzer of a data-acquisition system (Burleigh DAS 1) for accumulating the spectral data in the form of photon counts versus frequency or channel number. Feedback electronics associated with the data-acquisition system automatically compensated for drifts in the laser frequency and separation/alignment of the Fabry-Perot reflectors. This feature permitted continuous spectral accumulation for arbitrarily long periods of time (Gammon and others, 1978). A block diagram of the optical set-up can be found in a previous publication on artificial ice (Gammon and others, 1980).

The natural ice samples were held in a precision rectangular $(1 \mathrm{~cm} \times 1 \mathrm{~cm} \times 3.2 \mathrm{~cm})$ spectrosil optical cell which was enclosed in a specially designed housing and cooling system (substantially different from the cylindrical cell arrangement used for the artificial ice experiments (Gammon and others, 1980)). The sample housing was built to accommodate small ice chips of arbitrary shape. The housing also provided a high degree of flexibility in positioning ice samples relative to the Brillouin scattering optics. This flexibility was essential in order to avoid optical flaws in the path of the incident or scattered laser radiation and to select specific scattering volumes within heterogeneous samples.

The principal features of the sample housing are illustrated in Figure 1. Cooling and temperature control were provided by a combination of three thermoelectric modules for which 


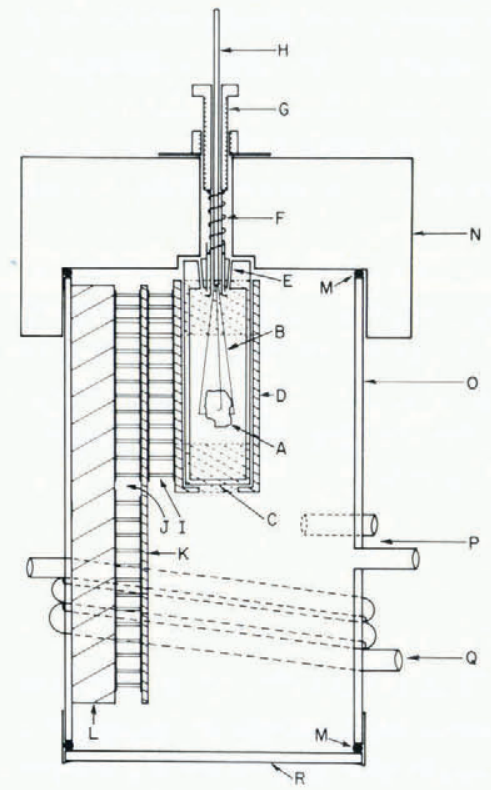

Fig. 1. Sample housing and cooling system for Brillouin spectroscopy in natural ice samples. $A$-ice sample; $B$-indium-coated steel wires; $C$-Spectrosil optical cell; $D$-copper cell enclosure and heat sink; $E$-teflon stopper; $F$-coil sping; $G$-hex bolt; $H$-stainless steel tube; I-thermoelectric module for temperature control; $J$-thermoelectric modules for cooling; $K$-copper plate; $L$-semirounded brass plate; $M$-O-ring seal; $N$-brass cover; $O$-copper cylindrical outer housing; $P$-dry $\mathrm{N}_{2}$ input and output; $Q$-cooling water pipe.

the low-temperature contact was a copper enclosure (D) immediately surrounding the sample cell, and the high-temperature heat sink consisted of the water-cooled outer enclosure (O) made of copper. The temperature of the sample was monitored by a (in situ) calibrated thermistor attached to the enclosure D. The sample temperature could be maintained within a range of \pm 0.2 deg during spectral accumulation.

Thermal contact between the suspended ice chip and the cell walls was provided by a liquid in which the sample was immersed. The most appropriate immersion liquid was selected on the basis of several required physical properties: namely optical transparency, minimal absorption or scattering of X-rays, immiscibility with water, a refractive index precisely matching that of ice, and a liquid range at atmospheric pressure which included the desired sample temperature. The particular liquid, 1, 2-dichlorotetrafluoroethane (Freon 114) met all these requirements with the exception of X-ray transparency, and hence was used in some of the work on sea ice where Laue diffraction photographs were not required. In all other work, 2, 2-dimethylpropane (neopentane) and perfluoromethylcyclohexane were mixed in the ratio of $5: 8$, respectively, to match the refractive index of ice and thereby permit the incident and scattered light to pass undeflected through the irregular surface of the ice chip.

An assembly at the top of the sample enclosure permitted rapid insertion of the ice into the cell as well as subsequent raising and lowering of the sample, and rotation of the sample by measured amounts about a vertical axis (parallel to the incident laser beam). A releasable gripping device made from thin indium-coated steel wires was used to hold the sample. A fused quartz bottom plate allowed the incident laser beam to enter the cell, while scattered light exited through a $2 \mathrm{~cm}$ Mylar covered hole drilled in the side of the housing D. Moisture accumulation on the windows and other internal cold surfaces was prevented by a continuous flow of vaporized liquid nitrogen through the enclosure.

Careful optical alignment of the sample cell was necessary in order to ensure accurate 
knowledge of the Brillouin scattering geometry. The outer cell housing was consequently mounted on an $X-Y$ translation stage to permit small adjustments of the sample position relative to the detection optics. A quartz refracting plate of appropriate thickness was also inserted in the path of the collected light for similar reasons. Rotation of this plate about an axis normal to the plane of scattering resulted in a finely controlled translation of the region of observation along the path of the incident light.

The precise orientation of a given monocrystal was determined by the Laue X-ray diffraction technique. The required X-ray source (Philips MG101), lead collimator, and camera (Polaroid XR-7) were accurately aligned on the axis of the optical system used to collect the scattered light. The orientation of the crystallographic axes with respect to a laboratory coordinate system was calculated from the positions of spots on the Laue photograph using a program written for the HP 9825 electronic calculator (Cullity, 1956; Gammon, unpublished [a], [b]).

Brillouin spectra were recorded for each of several (known) orientations of single crystals of glacier ice and lake ice. Since the directional dependence of velocities of sound waves in a hexagonal crystal involves only the angle $\gamma$ between the acoustic wave vector and the crystal $c$-axis (Landau and Lifshits, 1959; Musgrave, 1970), efforts mere made to correlate the highresolution Brillouin spectra with a series of $\gamma$ values distributed over the full $\left(0^{\circ}-90^{\circ}\right)$ range. The spectra were typically obtained in time intervals of the order of a few hours and showed the longitudinal, and usually one or both transverse Brillouin components. The resulting frequencyshift data were analyzed to yield the elastic constants using least-squares fitting techniques to invert the closed-form equations given by Musgrave (1970). A typical Brillouin spectrum showing all three components is shown in Figure 2.

The very poor optical and crystallographic quality of the sea ice necessitated substantial changes in the procedures for the acquisition and analysis of Brillouin data. X-ray orientations were not obtained since the Laue photographs could not be interpreted to yield crystal orientation. However, acoustic data from hexagonal monocrystalline grains of unknown

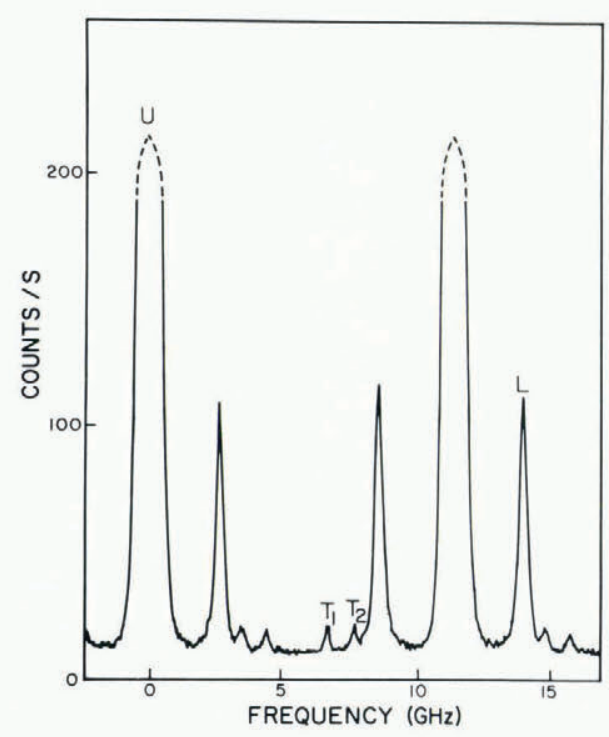

Fig. 2. Representative Brillouin spectrum from Mendenhall ice at $-16^{\circ} \mathrm{C}$. One and a half overlapping orders are shown, with two central components. $L$ designates the longitudinal Brillouin component and $T_{1}$ and $T_{2}$ the transverse components as shifted from the central component $U$. The intensity ratio $U: L=150$. 
orientation can be fully analyzed via procedures which have been described and demonstrated in a recent publication (Gammon and others, 1981[b]). Acoustic data consisting of simultaneous velocity measurements of two independent acoustic modes propagating in a single crystallographic direction are required for this purpose. This corresponds to the usual case where more than one Brillouin component is observed on a single spectrum. In particular, however, the data must include five or more pairs of frequency shift measurements of the form $\left(T_{1}, L\right)$, $\left(T_{2}, L\right)$, or $\left(T_{1}, T_{2}\right)$ where at least two pairs of measurements must include $T_{1}$. A least-squares fit procedure is then used to determine all five elastic constants.

Before a Brillouin spectrum could be obtained from sea-ice samples a suitably clear region for the scattering volume had to be located. More specifically, it was necessary to ensure that neither the incident nor the scattered light encountered any significant obstruction along their respective paths towards and away from the scattering volume. This usually required a careful search procedure which involved both the precise positioning of the sample via the $X-Y$ translation stage, and the precise selection of the desired scattering volume by rotation of the quartz refracting plate.

An example of a Brillouin spectrum from sea ice is shown in Figure 3. The accumulation times usually exceeded $24 \mathrm{~h}$. For some of the spectra the Fabry-Perot interferometer was switched from the three-pass to the five-pass mode of operation. The segmented time base feature of the DAS-1 system was also used to reduce the time required to obtain a suitable signal-tonoise ratio in the transverse components.

A uniform sample temperature of $(-16 \pm 0.5)^{\circ} \mathrm{C}$ was chosen for the Brillouin spectroscopic measurements of the elastic moduli for each type of natural ice. This temperature was the same as that used by Jona and Scherrer (1952) in their determination of ice elastic moduli and lay within the range of temperatures investigated by Dantl (1969) and by Bass and others (1957). As well, $-16^{\circ} \mathrm{C}$ lies within the range of those temperatures most frequently associated with the

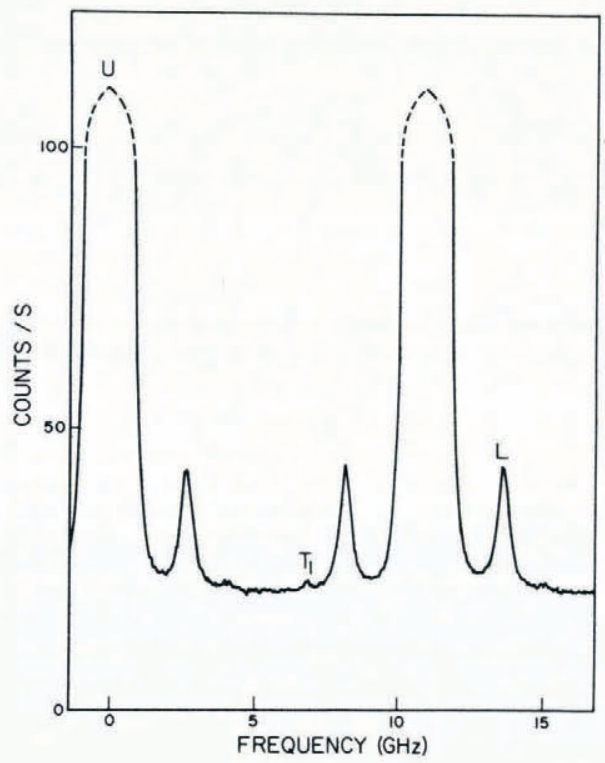

Fig. 3. Representative Brillouin spectrum from sea ice (taken over $24 \mathrm{~h}$ ). One and a half overlapping orders are shown. $L$ designates the longitudinal Brillouin component and $T_{1}$ the transverse component as shifted from the central component $U$. The intensity ratio $U: L=2500$. 
occurrence of ice in the natural environment. The elastic moduli determined at $-16^{\circ} \mathrm{C}$ can be corrected to correspond to a range of temperatures using Dantl's (1969) temperature correction coefficients.

\section{RESULTS AND ANALYSIS}

\section{Glacier ice}

One of the glacier ice samples was taken from Mendenhall Glacier in Alaska. Mendenhall Glacier is a temperate glacier providing ideal conditions for the growth and subsequent annealing of large unflawed ice monocrystals. Prolonged annealing at the freezing point has reduced impurity concentrations in melt water from monocrystals of Mendenhall ice to levels resembling those in distilled water (Higashi, 1969). Hence, crystal quality and age are the principal factors distinguishing Mendenhall ice from the artifical samples used in the previously reported Brillouin experiment (Gammon and others, 1980). A second type of glacier ice, namely that from an iceberg (off the coast of Newfoundland) was selected for use in a few measurements but was not subject to detailed study.

Samples of the Mendenhall ice were provided by the Cold Regions Research and Engineering Laboratory (CRREL) of Hanover, New Hampshire. The samples were collected in the summer of 1965 and stored at $-35^{\circ} \mathrm{C}$ until September 1979, when they were shipped by air to St John's Newfoundland in an insulated box. Pending their use in the Brillouin experiment the samples were stored for one month in a chest freezer at $-25^{\circ} \mathrm{C}$.

The selected working samples of Mendenhall ice were monocrystalline and completely free of optical imperfections. Laue photographs showed large uniform oval spots, typical of an unstraired crystal, and crystal orientations could readily be determined to facilitate analysis of the Brillouin data.

A total of 18 Brillouin spectra were obtained from two crystals of Mendenhall ice. The crystals were mounted so that subsequent rotation about the vertical axis permitted by the apparatus yielded a good distribution in values of the angle $\gamma$ (see Table I). The second crystal was housed in the apparatus for a total of $30 \mathrm{~d}$. The Brillouin spectra showed no evidence of any change in elastic properties occurring over this period.

The excellent optical quality of the Mendenhall ice facilitated observation of at least one transverse commponent in all but one of the 18 Brillouin spectra. In 10 of the spectra, both transverse components were observed. A total of 45 Brillouin frequency-shift measurements were obtained, and the values are listed in Table I. The estimated standard deviation in the measurements of frequency shift was $\pm 0.040 \mathrm{GHz}$.

Elastic constants were least-squares fitted to the data in Table I. The resulting curves of frequency shift (sound velocity) versus $\gamma$ are shown in Figure 4. Before calculating the elastic constants, it was necessary to specify values for the density $\rho$ and refractive index $n$ of Mendenhall ice at $-16^{\circ} \mathrm{C}$. Precise measurements of the density of 11 apparently perfect monocrystalline samples of Mendenhall ice were made by Butkovich (1955) at temperature near $-4{ }^{\circ} \mathrm{C}$. These values, corrected to correspond to a temperature of $-3.5^{\circ} \mathrm{C}$, yielded an average density of $917.18 \mathrm{~kg} \mathrm{~m}^{-3}$. The linear thermal expansion coefficients of several types of ice were measured by Butkovich (1959) and averaged to yield an equation for the expansion coefficient over the temperature range $0{ }^{\circ} \mathrm{C}$ to $-30^{\circ} \mathrm{C}$. This equation was used to produce the following 
TABLE I. BRILlouin SPECTROSCOPIC DATA For Mendenhall ICE, $-16{ }^{\circ} \mathrm{C}$

\begin{tabular}{|c|c|c|c|c|c|c|}
\hline \multicolumn{3}{|c|}{ Euler angles } & & \multicolumn{3}{|c|}{ Brillouin frequency shifts } \\
\hline $\begin{array}{c}\varphi \\
\mathrm{deg}\end{array}$ & $\begin{array}{c}\theta \\
\operatorname{deg}\end{array}$ & $\begin{array}{c}\psi \\
\mathrm{deg}\end{array}$ & $\begin{array}{c}\gamma \\
\operatorname{deg}\end{array}$ & $\begin{array}{c}\mathrm{L} \\
\mathrm{GHz}\end{array}$ & $\begin{array}{c}\mathrm{T}_{1} \\
\mathrm{GHz}\end{array}$ & $\begin{array}{c}\mathrm{T}_{2} \\
\mathrm{GHz}\end{array}$ \\
\hline \multicolumn{7}{|c|}{ 1st crystal: } \\
\hline 216.7 & 78.0 & 129.8 & 65.9 & 13.77 & 6.91 & 7.30 \\
\hline 186.4 & 79.2 & 130.1 & 56.1 & 13.62 & 6.83 & - \\
\hline 235.8 & 77.3 & 129.8 & 76.6 & 13.91 & - & 6.86 \\
\hline 259.8 & 76.9 & 129.1 & 87.8 & 13.99 & - & 6.50 \\
\hline 4.0 & 77.5 & 125.3 & 32.7 & 13.82 & 6.62 & 7.54 \\
\hline \multicolumn{7}{|c|}{ 2nd crystal: } \\
\hline 132.4 & 79.2 & 240.7 & 70.3 & 13.85 & - & 6.94 \\
\hline 200.7 & 77.9 & 243.1 & 60.1 & 13.76 & 6.91 & - \\
\hline 297.8 & 74.2 & 239.0 & 59.4 & 13.69 & - & 7.52 \\
\hline 125.6 & 112.5 & 271.8 & 49.4 & 13.61 & 6.78 & 7.79 \\
\hline 178.4 & 113.3 & 273.9 & 21.7 & 14.26 & 6.61 & 7.16 \\
\hline 132.5 & 115.3 & 272.4 & 42.8 & 13.67 & - & - \\
\hline 191.8 & 112.1 & 273.9 & 24.9 & 14.19 & 6.60 & 7.24 \\
\hline 211.7 & 111.2 & 273.3 & 35.3 & 13.89 & 6.69 & 7.67 \\
\hline 218.4 & 110.9 & 273.1 & 39.7 & 13.78 & 6.74 & 7.82 \\
\hline 71.4 & 110.5 & 264.4 & 87.9 & 14.05 & - & 6.53 \\
\hline 52.6 & 109.9 & 262.9 & 80.6 & 13.99 & 6.97 & 6.74 \\
\hline 227.0 & 110.7 & 267.2 & 45.5 & 13.63 & 6.77 & 7.86 \\
\hline 201.6 & 111.8 & 266.6 & 29.2 & 14.03 & 6.62 & 7.44 \\
\hline
\end{tabular}

expression for the temperature dependence of the density of ice:

$\rho^{-1}=\rho_{0}^{-1}\left[1+1.576 \times 10^{-4} T-2.778 \times 10^{-7} T^{2}+8.850 \times 10^{-9} T^{3}-1.778 \times 10^{-10} T^{4}\right]$.

In the above equation, $\rho$ denotes density, $\rho_{0}$ denotes the density at $0^{\circ} \mathrm{C}$, and $T$ is the temperature in Celsius degrees. Accordingly, the value quoted above for the density of Mendenhall ice at $-3.5^{\circ} \mathrm{C}$ was found to correspond to a density of $919.10 \mathrm{~kg} \mathrm{~m}^{-3}$ at $-16^{\circ} \mathrm{C}$.

The uncertainty in density determination for individual samples of Mendenhall ice was estimated by Butkovich (1955) to be $\pm 0.021 \mathrm{~kg} \mathrm{~m}^{-3}$. However, the empirical standard deviation in the density measurements from the 11 perfect monocrystals was $\pm 0.056 \mathrm{~kg} \mathrm{~m}^{-3}$ indicating a

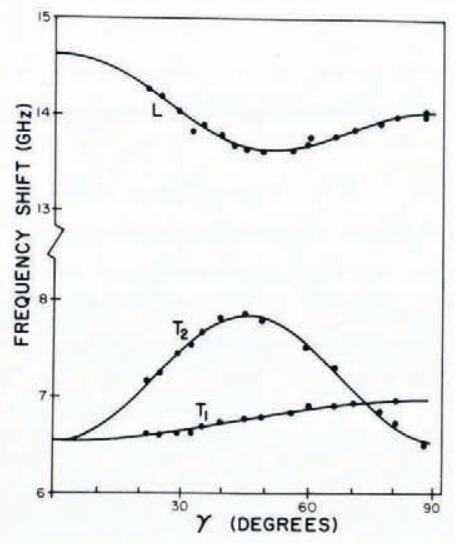

Fig. 4. Measured Brillouin frequency shifts (indicated by the solid dots) versus angle $\gamma$ and best-fit curves for Mendenhall ice at $-16^{\circ} \mathrm{C}$. 
small but measurable difference in density among the samples. The maximum standard deviation in values of the linear thermal expansion coefficient given by the expression from Butkovich (1955) leading to Equation (2) is $\pm 1.5 \%$. Hence an uncertainty of $\pm 0.03 \mathrm{~kg} \mathrm{~m}^{-3}$ in the calculated density of Mendenhall ice at $-16^{\circ} \mathrm{C}$ results from the application of Equation (2) in correcting the density from $-3.5^{\circ} \mathrm{C}$. A final contribution to the error in the density results from uncertainty of $\pm 0.5 \mathrm{deg}$ in the temperature of the ice sample. This gives rise to an uncertainty of $\pm 0.08 \mathrm{~kg} \mathrm{~m}^{-3}$ in the density. Combining the four statistically independent error terms noted above yields a value of $919.10 \pm 0.10 \mathrm{~kg} \mathrm{~m}^{-3}$ for the density of the Mendenhall ice samples used in the present determination of elastic moduli.

The value for the refractive index of ice at $-3^{\circ}$ stated in Gammon and others (1980) was $n=1.312 \pm 0.001$. This value, when corrected using the Lorentz-Lorenz relation (Jackson, 1975), for the increase in density which occurs upon cooling becomes $n=1.3127 \pm 0.001$ for ice at $-16{ }^{\circ} \mathrm{C}$. Values for the remaining parameters in the Brillouin equation, namely $\lambda=5.145 \times 10^{-7} \mathrm{~m}, \alpha=(90 \pm 0.2)^{\circ}$, are taken as in Gammon and others (1980).

The elastic moduli determined for Mendenhall ice at $(-16 \pm 0.5){ }^{\circ} \mathrm{C}$ are given below (see also Table IV):

$$
\left.\begin{array}{l}
c_{11}=139.13 \pm 0.22 \% \\
c_{12}=70.26 \pm 0.74 \% \\
c_{13}=58.01 \pm 0.52 \% \\
c_{33}=150.59 \pm 0.32 \% \\
c_{44}=30.11 \pm 0.46 \%
\end{array}\right\} \times\left(10^{8} \pm 0.38 \%\right) \mathrm{N} \mathrm{m}^{-2}
$$

The error terms associated with the individual elastic constants were determined empirically as a standard deviation in the least-squares fit routine. This random error resulted from uncertainty in the shift measurements and in the orientation of the ice crystals. The systematic error, common to all five elastic constants was calculated from the uncertainties in $\rho, n$, and $\alpha$ indicated above. The systematic error was primarily due to uncertainty in the scattering angle $\alpha$.

The measurements for iceberg ice were consistent with the above results.

\section{Lake ice}

Ice crystal growth conditions in the fresh-water lake environment are considerably more complex than those existing in a temperate glacier. Rapid temperature changes lead to variable and high freezing rates and large thermal gradients. Thus grain size is irregular and often small. Crystal growth may be modified by dissolved gaseous and solid impurities in the water. The Brillouin experiment on lake ice was consequently undertaken to determine whether non-ideal crystal growth conditions in the fresh-water lake environment modified the elastic properties of monocrystalline lake ice relative to those in glacier ice.

A sample of lake ice was obtained from Paddy's Pond, near St John's. The sample was taken from the $0.4 \mathrm{~m}$ thick ice cover near the middle of the lake using an ice auger and saw. The sample was stored for five months in a chest freezer at $-25^{\circ} \mathrm{C}$.

The bulk sample of lake ice contained air bubbles dispersed throughout its volume, but primarily concentrated in horizontal layers. The working sample was chipped from a layer of minimum bubble density and included no visible air bubbles. The sample appeared clear 
although optical flaws were present as evidence by occasional bright scattering in the focused laser beam. These flaws were noted to be due to either tiny air bubbles or particles of embedded foreign (solid) material. The Laue photographs showed spots of slightly less regular shape than for glacier ice. The photographs were again analyzed to determine the crystal orientations. The sample was in fact found to be bicrystalline, with a flat grain boundary clearly visible through crossed polaroids, and dividing the volume of the sample in the approximate ratio $1: 3$. The presence of this boundary was neglected in the measurements by choosing the scattering volume to lie a few millimetres above it in the larger monocrystal.

The Brillouin spectra from the lake-ice sample did not differ significantly from the Mendenhall ice spectra in terms of line widths or relative intensities of the various spectral components. A total of 14 Brillouin spectra were obtained from a single bicrystalline sample of lake ice. Again the sample was mounted and rotated so that a good distribution in values of $\gamma$ (see Table II) was obtained, thereby facilitating accurate determination of the elastic moduli. All but two of the 14 Brillouin spectra showed at least one transverse component while three of the spectra showed both. A total of 29 Brillouin frequency shift measurements were obtained from the lake-ice sample. The estimated standard deviation in the frequency-shift measurements was $\pm 0.044 \mathrm{GHz}$.

Elastic constants were least-squares fitted to the data in Table II to yield the curves of leastsquares frequency shift versus $\gamma$ shown in Figure 5. With the exception of the density, the muliplicative parameters in the Brillouin equation, along with their uncertainties, were set equal to those values used in the determination of elastic constants for Mendenhall ice. The density was calculated from the value used for artificial ice at $-3{ }^{\circ} \mathrm{C}$ (Gammon and others, 1980) since an accurate measurement of the microscopic density of lake ice could not be obtained. The density value therefore reflected results of several measurement techniques applied to a variety of types of ice and included an appropriately large uncertainty. The previously quoted density of ice at $-3{ }^{\circ} \mathrm{C}, 917.5 \pm 1.5 \mathrm{~kg} \mathrm{~m}^{-3}$, was corrected to correspond to $-16^{\circ} \mathrm{C}$ via Equation (2). Accordingly, the density of lake ice at $-16 \pm 0.5^{\circ} \mathrm{C}$, neglecting the insignificant uncertainty in temperature and thermal expansion coefficient, was taken to be $919.5 \pm 1.5 \mathrm{~kg} \mathrm{~m}^{-3}$.

TABLE II. BRILlouin SPECTROSCOPIC DATA FOR LAKE ICE (PADdy's POND), $-16{ }^{\circ} \mathrm{C}$

\begin{tabular}{|c|c|c|c|c|c|c|}
\hline & uler ang & & & Bri & requen & \\
\hline $\begin{array}{c}\varphi \\
\mathrm{deg}\end{array}$ & $\begin{array}{c}\theta \\
\mathrm{deg}\end{array}$ & $\begin{array}{c}\psi \\
\operatorname{deg}\end{array}$ & $\begin{array}{c}\gamma \\
\mathrm{deg}\end{array}$ & $\begin{array}{c}\mathrm{L} \\
\mathrm{GHz}\end{array}$ & $\begin{array}{c}\mathrm{T}_{1} \\
\mathrm{GHz}\end{array}$ & $\begin{array}{c}\mathrm{T}_{2} \\
\mathrm{GHz}\end{array}$ \\
\hline 72.6 & 106.2 & 251.7 & 89.7 & 13.94 & - & - \\
\hline 60.6 & 105.3 & 251.4 & 81.5 & 13.93 & - & 6.68 \\
\hline 7.7 & 102.9 & 251.0 & 58.3 & 13.60 & 6.82 & - \\
\hline 178.7 & 106.6 & 254.3 & 28.5 & 14.00 & 6.61 & - \\
\hline 126.4 & 106.4 & 251.1 & 53.0 & 13.57 & - & - \\
\hline 101.0 & 103.9 & 249.1 & 72.5 & 13.87 & - & 6.74 \\
\hline 112.5 & 105.0 & 249.3 & 63.6 & 13.74 & - & 7.35 \\
\hline 124.2 & 104.9 & 249.9 & 55.5 & 13.65 & - & 7.68 \\
\hline 135.9 & 105.9 & 250.5 & 47.0 & 13.62 & 6.82 & - \\
\hline 148.0 & 104.9 & 250.4 & 40.4 & 13.72 & 6.78 & - \\
\hline 156.2 & 105.2 & 251.5 & 35.9 & 13.81 & 6.72 & 7.82 \\
\hline 167.1 & 104.8 & 251.3 & 32.1 & 13.89 & 6.66 & 7.65 \\
\hline 179.7 & 104.5 & 252.3 & 30.5 & 13.99 & 6.66 & 7.57 \\
\hline 74.7 & 104.7 & 247.8 & 89.9 & 14.04 & - & 6.52 \\
\hline
\end{tabular}




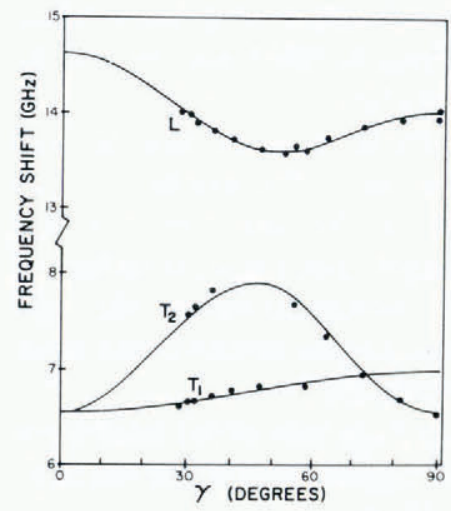

Fig. 5. Measured Brillouin frequency shifts (indicated by the solid dots) versus angle $\gamma$ and best-fit curves for lake ice at $-16^{\circ} \mathrm{C}$.

The elastic moduli determined for lake ice at $-16 \pm 0.5^{\circ} \mathrm{C}$ are given below (see also Table IV). The error has been divided into its unsystematic and systematic components as above.

$$
\left.\begin{array}{l}
c_{11}=138.76 \pm 0.28 \% \\
c_{12}=69.79 \pm 1.33 \% \\
c_{13}=56.57 \pm 0.76 \% \\
c_{33}=150.71 \pm 0.47 \% \\
c_{44}=30.24 \pm 0.73 \%
\end{array}\right\} \times\left(10^{8} \pm 0.41 \%\right) \mathrm{N} \mathrm{m}^{-2}
$$

Because of the good agreement between the values quoted above and those quoted for Mendenhall ice and for artificial ice (see Gammon and others, 1980), an intended second determination of the elastic moduli of lake ice, utilizing a different sample, was not carried out.

\section{Sea ice}

The high concentration of dissolved impurities in ocean water gives rise to ice crystal growth conditions very different from those present in any fresh-water environment. Since several types of impurity ions are present in concentrations far exceeding those which may be dispersed uniformly within the ice crystals, the freezing process is accompanied by the expulsion of these ions to regions which have not solidified. The resulting substance is heterogeneous, consisting of regions of ice interspersed with air bubbles and liquid inclusions containing concentrated dissolved (and at lower temperatures precipitated) impurities.

A sample of sea ice collected from the Weddell Sea (lat. $73^{\circ} 56^{\prime}$ S., long. $42^{\circ} 46^{\prime} \mathrm{W}$.) in the Antarctic was provided by CRREL. The sample was the bottom $0.14 \mathrm{~m}$ of a $1.5 \mathrm{~m}$ core drilled in what was characterized as first-year columnar sea ice, sampled at the end of the first summer (personal communication in 1980 from G. Lemieux). The temperature of the sample at the time of collection was around $-2^{\circ}$ to $-3^{\circ} \mathrm{C}$. Following collection in mid-February 1980 , the sample was stored at $-17.8^{\circ} \mathrm{C}$ for about two months while in transit to CRREL and was subsequently stored at $-28.9^{\circ} \mathrm{C}$ for about three months prior to being flown to St John's. While awaiting its use in the Brillouin experiment, the sample was held for one week at $-25^{\circ} \mathrm{C}$ in a freezer.

The bulk sample of sea ice contained a high density of tiny air bubbles and other optical flaws making it translucent even when viewed in sections only $0.005 \mathrm{~m}$ thick. In observation 
through crossed polaroid filters, most samples chipped from the bulk appeared polycrystalline with grains of millimetre dimensions in some cases. Brine inclusions could not be visually identified in the chip samples but nevertheless were most probably present.

Laue photographs from the samples of sea ice used in the Brillouin measurements showed numerous small, irregular, and smeared spots indicating a fine-grained polycrystalline texture with considerable disruption of the constituent monocrystals. Diffraction spots of size comparable to the spot formed by the undeflected X-ray beam suggest that a few crystallites of multi-millimetre dimensions were also present in the samples. As mentioned before, the Laue photographs could not be interpreted to yield crystal orientation and hence different and novel analysis of the Brillouin data was required (Gammon and others, 1981[b]).

The poor optical quality of the samples was reflected in the very large ratio of the intensity of the unshifted central component to that of the longitudinal Brillouin components; it was ten times greater than that obtained in Brillouin spectra from any other type of ice.

A total of 23 Brillouin spectra of sea ice were obtained from two samples. These spectra yielded 19 pairs and 4 triples of acoustic velocity measurements or a total of 50 Brillouin frequency-shift measurements. The overall error in frequency-shift measurements was estimated to be \pm 1 channel or $\pm 0.03 \mathrm{GHz}$.

Table III shows the data for sea ice (as well as simulated values for the angle $\gamma$ ). The

TABLE III. BRILLOUIN SPECTROSCOPIC DATA FOR SEA ICE, $-16^{\circ} \mathrm{C}$

\begin{tabular}{rccc}
\multicolumn{5}{c}{ Brillouin frequency shifts } \\
$\mathrm{L}$ & $\mathrm{T}_{1}$ & $\mathrm{~T}_{2}$ & $\gamma$ \\
$\mathrm{GHz}$ & $\mathrm{GHz}$ & $\mathrm{GHz}$ & $\mathrm{deg}$ \\
1st crystal: & & & \\
14.006 & - & 6.651 & 76.7 \\
2nd crystal: & & & \\
13.775 & 6.913 & - & 59.4 \\
13.592 & 6.758 & - & 47.3 \\
13.893 & 6.910 & - & 65.3 \\
13.952 & 6.904 & - & 68.2 \\
13.867 & 6.619 & 7.522 & 32.3 \\
13.539 & 6.771 & - & 47.5 \\
13.663 & 6.760 & - & 46.2 \\
13.747 & 6.756 & - & 38.7 \\
13.804 & 6.658 & 7.667 & 35.5 \\
13.927 & 6.955 & - & 67.1 \\
14.068 & 6.976 & - & 74.5 \\
13.663 & 6.840 & - & 50.8 \\
13.981 & 6.942 & - & 69.8 \\
14.013 & 6.691 & 7.367 & 27.0 \\
13.945 & - & 6.759 & 72.4 \\
14.035 & 6.942 & - & 72.5 \\
13.927 & - & 6.991 & 69.1 \\
13.709 & 6.764 & 7.843 & 42.2 \\
13.618 & 6.837 & - & 48.8 \\
14.028 & - & 6.831 & 73.5 \\
13.981 & - & 6.867 & 71.9 \\
13.916 & - & 7.079 & 67.8
\end{tabular}


frequency-shift data were converted to the format $\left(\mathrm{L}^{2}, \mathrm{~T}_{1}^{2}\right.$, and $\left.\mathrm{T}_{2}^{2}\right)$, as required for analysis via the technique described in Gammon and others (1981[b]). Elastic constants were subsequently least-squares fitted. To facilitate plotting of the experimental data in the same format used for the fresh-water ice samples, simulated values of $\gamma$ were assigned to each frequency-shift measurement. The $\gamma$ values were calculated via equations (1), (2), or (3) in Gammon and others (1981[b]) from pairs of acoustic velocities satisfying equation (6) or equation (10) in Gammon and others (1981[b]). Figure 6 shows the curves of Brillouin frequency shift versus $\gamma$ specified by the elastic constants determined for sea ice. The distribution of the data over values of the angle $\gamma$ was fairly good, especially in view of the fact that prior knowledge of crystal orientation could not be used as a guide in selecting desirable angles of rotation of the sample about the vertical axis of the sample housing. The $\gamma$ values obtained were to a large extent random, but some selection was achieved by rejecting Brillouin spectra which appeared, after a short period of accumulation, to be duplicating existing data.

Accurate values could not be obtained for either the density or the refractive index of sea ice. hence the values were set equal to those used in the analysis of the Brillouin data from lake ice.

The elastic constants determined for local, apparently homogeneous regions of ice within a sea ice sample are given below (see also Table IV):

$$
\left.\begin{array}{l}
c_{11}=142.7 \pm 4.8 \% \\
c_{12}=73.2 \pm 6.9 \% \\
c_{13}=59.5 \pm 2.5 \% \\
c_{33}=147.4 \pm 1.4 \% \\
c_{44}=29.8 \pm 1.7 \%
\end{array}\right\} \times 10^{8} \mathrm{~N} \mathrm{~m}^{-2}
$$

The quoted uncertainties were calculated numerically.

The numerical error calculation was based on 25 computer-simulated repetitions of the process of determining the elastic constants. In each repetition, a normally distributed random number with mean of zero and standard deviation $\pm 0.03 \mathrm{GHz}$ was added to each of the 50 frequency shift measurements listed in Table III. The uncertainty in an individual elastic constant was then taken to be the square root of the empirical second moment about the mean of the set of 25 determinations of that elastic constant. The numerical error analysis not only yielded

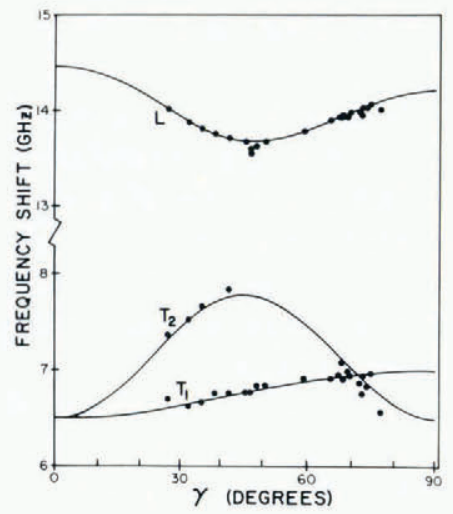

Fig. 6. Measured Brillouin frequency shifts (indicated by the solid dots) versus synthesized $\gamma$ values and best-fit curves for sea ice $-16^{\circ} \mathrm{C}$. 
estimates for the standard deviations, but also yielded further information on the probability distributions of the values for the elastic constants. In particular, a significant statistical bias in the estimates for each of three of the elastic constants was noted. The mean of the set of 25 determinations of $c_{11}$ was $6 \%$ higher than the least squares value for $c_{11}$. Similarly, the mean for $c_{12}$ was $8 \%$ high, the mean for $c_{33}$ was $2 \%$ low, while the means for $c_{13}$ and $c_{44}$ were not significantly biased.

The above results imply that the transformations used in calculating the elastic constants translate unbiased error in sound velocity measurements into biased expectation values for the final results. More specifically, the values determined for $c_{11}$ and $c_{12}$ are likely to be high, the value determined for $c_{33}$ is likely to be low while the expected values of $c_{13}$ and $c_{44}$ are likely unbiased. These observations should be noted when comparing the elastic constants determined for sea ice with those determined for the fresh-water ice samples where knowledge of crystal orientation obviated the need for application of the methods of Gammon and others (1981[b]).

\section{Discussion}

\section{Experimental observations}

The results of four independent determinations of the elastic moduli of ice by Brillouin spectroscopy are quoted above and in Table IV. The ice samples utilized in these measurements represented widely varying environments of formation. Aside from the resultant variations in crystal quality and purity of the samples, all experimental parameters except the temperature were kept as nearly constant as possible. Hence, conclusions regarding the dependence of the elastic properties of ice on the environment of formation can be drawn from the data obtained. The elastic constants of artificial ice have been corrected to correspond to a temperature of $-16^{\circ}$ using the temperature correction equations of Dantl (1969). The systematic and unsystematic components of the uncertainties in the elastic constants have been combined in Table IV. While the systematic error component is common to all five elastic constants determined for an individual sample, random variation in this component occurs among the sets of measurements from each of the four samples.

Inspection of the data listed in Table IV shows general agreement among the elastic moduli of the four ice samples determined by Brillouin spectroscopy. Among the 30 pairs of elastic constants which may be selected for comparison, 21 show agreement within the quoted uncertainties, that is within one standard deviation, while no pair is separated by more than 2.3 deviations. The maximum discrepancy is found in comparing $c_{13}$ for artificial ice with the corresponding value for lake ice.

It is thus concluded that no significant variation in the elastic moduli of local homogeneous regions in ice can be identified from the present results. In view of the wide range of conditions under which the samples studied were formed, it is further concluded that any differences exceeding $1 \%$ in the elastic properties of arbitrary samples of natural ice are almost certainly attributable to factors other than variability in the moduli of local homogeneous regions of ice. Curves showing $\Omega$ (Brillouin frequency shift) versus $\gamma$ (angle relative to $c$-axis), specified by the elastic constants determined for each of the four samples of ice, are shown in Figure 7.

The tendency of the elastic moduli of ice to decrease with sample age, as noted by Dantl (1969), has not been demonstrated in the present measurements. Accumulation of Brillouin data from the artificial ice crystals was commenced only a few hours following freezing and was 
Table IV. Measurements of the adiabatic elastic moduli of ICE IH

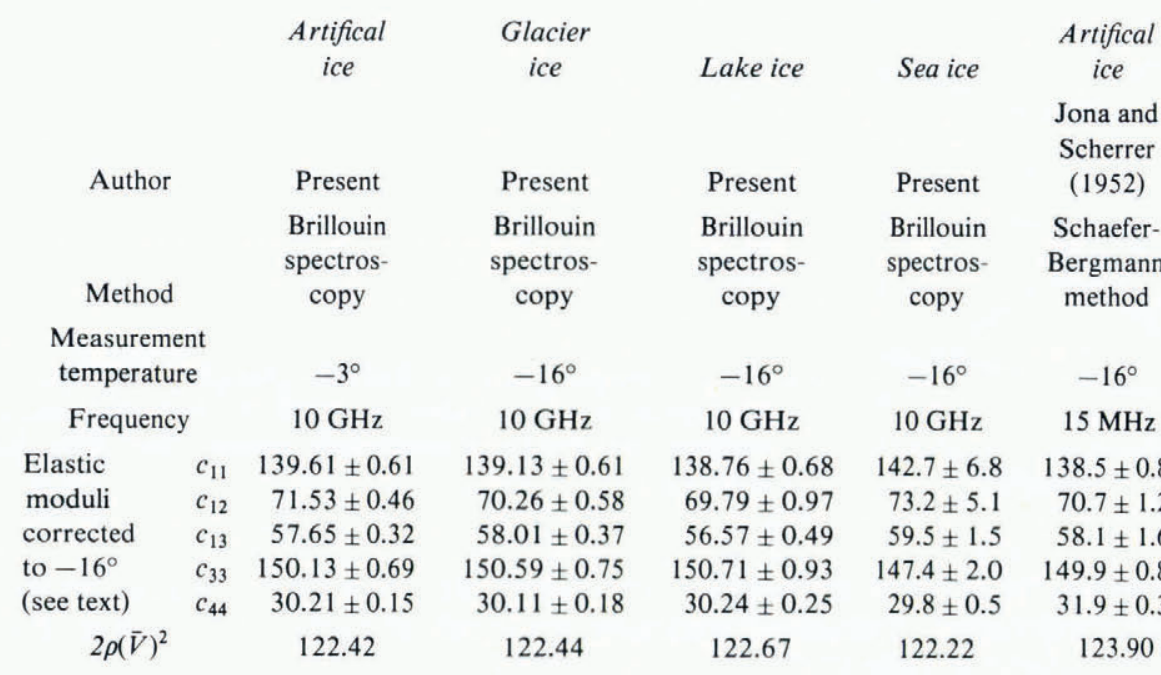

$\begin{array}{ccccc}\begin{array}{c}\text { Artificial } \\ \text { ice }\end{array} & \begin{array}{c}\text { Artificial } \\ \text { ice (aged) }\end{array} & \begin{array}{c}\text { Artificial } \\ \text { ice } \\ \text { Bass and }\end{array} & \begin{array}{c}\text { Artificial } \\ \text { ice }\end{array} & \begin{array}{c}\text { Lake ice } \\ \text { others }\end{array} \\ \begin{array}{c}\text { Querfurth } \\ (1957)\end{array} & \begin{array}{c}\text { Dantl } \\ (1969)\end{array} & \begin{array}{c}\text { Proctor } \\ (1964)\end{array} & \begin{array}{c}\text { Bogorodskiy } \\ (1964)\end{array} \\ \begin{array}{c}\text { Resonant } \\ \text { bars and }\end{array} & \text { Ultrasonic } & \text { Ultrasonic } & \text { Ultrasonic } & \text { Ultrasonic } \\ \text { plates } & \text { pulse } & \text { pulse } & \text { pulse } & \text { pulse } \\ -2^{\circ} \text { to } & -0.7^{\circ} \text { to } & 0^{\circ} \text { to } & -163^{\circ} \text { to } & \\ -30^{\circ} & -140^{\circ} & -20^{\circ} & -213^{\circ} & -15^{\circ} \\ 5 \mathrm{kHz}-50 \mathrm{kHz} & 5 \mathrm{MHz}-190 \mathrm{MHz} & 2 \mathrm{MHz}, 12 \mathrm{MHz} & 15 \mathrm{MHz} & 4 \mathrm{MHz} \\ 133 \pm 8 & 132.1 \pm 0.4 & 137.5 \pm 0.7 & 139.1 & 133.9 \pm 13 \\ 63 \pm 8 & 67.9 \pm 1.3 & 67.7 & 68.6 & 68.0 \pm 7 \\ 49 \pm 9 & 58.0 \pm 4.1 & 52.5 & 53.9 & 77.9 \pm 8 \\ 142 \pm 7 & 144.3 \pm 0.6 & 149.9 & 149.8 & 168.6 \pm 17 \\ 30.6 \pm 0.15 & 28.9 \pm 0.2 & 30.7 & 20.8 & 37.7 \pm 3 \\ 120.35 & 116.63 & 123.18 & 123.75 & 127.08\end{array}$

continued for up to six weeks. During such time, no appreciable change in the dependence of sound velocity on crystal orientation was noted. Furthermore, while samples of Mendenhall ice were presumably annealed at the freezing point for time periods greatly exceeding the eight months over which the samples of Dantl (1969) were aged, the agreement of their elastic constants with those of the unaged artificial ice samples is excellent.

The concentration of dissolved ionic solids in water at the time of freezing does not significantly affect the elastic properties of the resulting ice monocrystals. This conclusion arises from comparison of the elastic moduli of sea ice with the moduli determined for the three types of fresh-water ice. Clearly, the concentration of solid ionic impurities present at the time of freezing varies over several orders of magnitude between sea-water and the doubly distilled water 


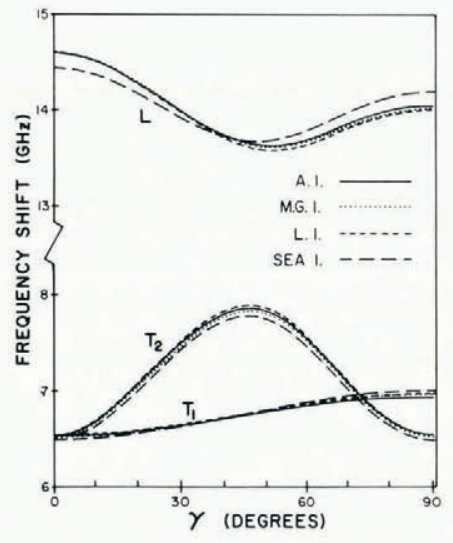

Fig. 7. Comparative plots of Brillouin frequency shift ( $\Omega$ ) versus propagation direction relative to c-axis $(\gamma)$ for sound waves in ice. artificial ice; M.G.I.-Mendenhall glacier ice; L.I.—lake ice; SEA I-ice.

used in growing the artificial ice samples. The glacier ice and lake ice samples presumably include intermediate levels of dissolved impurities. The results of partial water analyses from the four samples are listed in Table V.

It is concluded that the process of ion rejection accompanying freezing and subsequent annealing of the natural ice samples studied in the present work is, probably, relatively efficient. That is, it has reduced impurity concentrations to levels yielding insignificant or non-varying distortion of the ice crystal lattice as evidenced by the uniformity in the elastic properties of the four samples. Consequently, it appears that in assessing the microscopic elastic behaviour of most types of ice occurring in the natural environment, the presence of impurities in the water at the time of freezing can be disregarded. Of course, the bulk elastic properties will be strongly

TABLE V. ANALYSES OF MELTED ICE SAMPLES

\begin{tabular}{|c|c|c|c|c|c|}
\hline Sample & & $\begin{array}{c}\text { Artificial } \\
\text { ice } \\
\text { (before } \\
\text { freezing) } \\
\text { (a) }\end{array}$ & $\begin{array}{c}\text { Glacier ice } \\
\text { (melt water) } \\
\text { (b) }\end{array}$ & $\begin{array}{c}\text { Lake ice } \\
\text { (melt water) } \\
\text { (a) }\end{array}$ & $\begin{array}{c}\text { Sea ice } \\
\text { (melt water) } \\
\text { (c) }\end{array}$ \\
\hline Conductivity & & $10^{-2}(\Omega \mathrm{m})^{-1}$ & $10^{-4}(\Omega \mathrm{m})^{-1}$ & $10^{-3}(\Omega \mathrm{m})^{-1}$ & - \\
\hline $\mathrm{pH}$ & & 5.90 & - & 5.00 & - \\
\hline Impurity & $\mathrm{Na}^{+}$ & - & - & 0.60 & $2 \times 10^{3}$ \\
\hline concen- & $\mathrm{Cl}^{-}$ & - & 0.2 & 6 & $3 \times 10^{3}$ \\
\hline trations & $\mathrm{Ca}^{2+}$ & - & 1.5 & 0.11 & - \\
\hline in ppm & $\mathrm{SO}_{4}^{2-}$ & - & 0.8 & - & - \\
\hline by weight & $\mathrm{Mg}^{2+}$ & - & 0.02 & 0.03 & - \\
\hline & $\mathrm{Mn}$ & - & - & 0.01 & - \\
\hline & $\mathrm{Fe}$ & - & - & 0.03 & - \\
\hline & $\mathrm{K}^{+}$ & - & - & 0.07 & - \\
\hline & $\mathrm{NH}_{4}^{+}$ & - & - & 0.025 & - \\
\hline & $\mathrm{F}^{-}$ & - & - & 0.012 & - \\
\hline & $\mathrm{NO}_{3}^{-}$ & - & - & 0.005 & - \\
\hline
\end{tabular}

Analysis carried out by:

(a) Memorial University of Newfoundland Water Analysis Facility.

(b) Higashi (1969) and Maeno (1973).

(c) CRREL. 
influenced by air, brine, or salt inclusions which may be present in a given sample. While a discussion of the potential effects of such inclusions lies outside the scope of the present work, the results obtained here are immediately applicable in one respect. That is, they establish a relatively precise and experimentally verified limit for the elastic properties of porous ice (sea ice) as the fractional volume of the pores approaches zero. Such a limit forms an important component of most elastic models for sea ice (Weeks and Assur, 1967; Schwarz and Weeks, 1977).

The present Brillouin spectroscopic measurements indicate that disruption of ice crystals by strains exceeding the elastic limit does not give rise to significant volumes of ice possessing elastic properties differing from those of unstrained monocrystalline ice. Laue photographs from the sea-ice samples show considerable disruption of the constituent monocrystals. If this disruption extended continuously over volumes comparable to the Brillouin scattering volume, then the effects of the resulting change in the local symmetry of the ice could be expected to appear in the Brillouin spectra. No discrepancy (in terms of satisfying equations (6) and (10) in Gammon and others (1981[b])) was observed in the sound-velocity data determined from any of the Brillouin spectra of sea ice. In addition, Brillouin spectra from a sample of bubbly iceberg ice showed all three acoustic components having velocities satisfying the above-mentioned equations with the $S_{i}$ set equal to the quoted values for monocrystalline ice. The fact that crystal disruption does not appear to affect the observed local elastic properties of ice is probably a consequence of annealing or recrystallization which occurs following disruption.

Since no significant variation was observed among the elastic properties of the four ice samples studied, the four sets of elastic constants were averaged to form a single set for use in calculating the derived quantities discussed below. Each elastic constant in the averaged set was taken to be the arithmetic mean of four values for that constant, obtained from the four types of ice and weighted by the reciprocal of their respective standard deviations. The weighted mean values thus form the best estimates for the elastic moduli of an aribtrary ice sample which can be obtained from the present data.

\section{Derived parameters}

(a) Monocrystals

Table VI lists the weighted mean elastic constants calculated from the four sets of Brillouin measurements, along with several quantities derived from these elastic constants. Uncertainties in both the mean elastic constants and the derived quantities have been calculated assuming statistical independence of the uncertainties in the five individual elastic constants. The comments in the following paragraph pertain primarily to the procedures adopted in determining the various listed values.

The elastic compliance constants $s_{i j}$ are the elements of the matrix which is the inverse of the $6 \times 6$ matrix $\left[c_{i j}\right]$. The expression used for the $s_{i j}$ in terms of $c_{i j}$ were adapted from Nye (1957) as appropriate for hexagonal media.

The dynamic bulk modulus $K$ for media of hexagonal symmetry is given by

$$
K^{-1}=\left[3\left(c_{33}-c_{13}\right)+\left(c_{11}+c_{12}-c_{13}-c_{33}\right)\right] / c^{2}
$$

where $c=\left[\left(c_{11}+c_{12}\right) c_{33}-2 c_{13}^{2}\right]^{1 / 2}$. In such media, the linear compressibility $\beta$ depends on the angle $\gamma$ between the specified direction and the hexagonal axis. Consequently:

$$
\beta=\beta_{1}+\beta_{2} \cos ^{2} \gamma
$$


TABLE VI. ELASTIC PARAMETERS FOR ICE MONOCRYSTALS AT $-16^{\circ} \mathrm{C}$

\begin{tabular}{|c|c|c|}
\hline Property and units & Symbol & Value \\
\hline \multirow{5}{*}{$\begin{array}{l}\text { Dynamic elastic moduli } \\
\left(10^{8} \mathrm{~N} \mathrm{~m}^{-2}\right)\end{array}$} & $c_{11}$ & $139.29 \pm 0.41$ \\
\hline & $c_{12}$ & $70.82 \pm 0.39$ \\
\hline & $c_{13}$ & $57.65 \pm 0.23$ \\
\hline & $c_{33}$ & $150.10 \pm 0.46$ \\
\hline & $c_{44}$ & $30.14 \pm 0.11$ \\
\hline \multirow{5}{*}{$\begin{array}{l}\text { Dynamic elastic compliances } \\
\left(10^{-12} \mathrm{~m}^{2} \mathrm{~N}^{-1}\right)\end{array}$} & $s_{11}$ & $103.18 \pm 0.52$ \\
\hline & $s_{12}$ & $-42.87 \pm 0.45$ \\
\hline & $s_{13}$ & $-23.16 \pm 0.17$ \\
\hline & $s_{33}$ & $84.41 \pm 0.40$ \\
\hline & $s_{44}$ & $331.79 \pm 0.21$ \\
\hline Bulk modulus $\left(10^{8} \mathrm{~N} \mathrm{~m}^{-2}\right)$ & $K$ & $88.99 \pm 0.17$ \\
\hline Compressibility $\left(10^{-12} \mathrm{~m}^{2} \mathrm{~N}^{-1}\right)$ & $C$ & $112.38 \pm 0.21$ \\
\hline $\begin{array}{l}\text { Coefficients in expression for } \\
\text { linear compressibility (see text) }\end{array}$ & $\beta_{1}$ & $37.14 \pm 0.12$ \\
\hline$\left(10^{-12} \mathrm{~m}^{2} \mathrm{~N}^{-1}\right)$ & $\beta_{2}$ & $0.95 \pm 0.31$ \\
\hline \multirow{3}{*}{$\begin{array}{l}\text { Coefficients in expression for } \\
\text { reciprocal of Young's modulus } \\
\text { (see text) }\left(10^{-12} \mathrm{~m}^{2} \mathrm{~N}^{-1}\right)\end{array}$} & $e_{1}$ & 103.176 \\
\hline & $e_{2}$ & 79.108 \\
\hline & $e_{3}$ & 97.871 \\
\hline \multirow{7}{*}{$\begin{array}{l}\text { Coefficients in sound velocity } \\
\text { equations }(1)-(3) \text { of Gammon and } \\
\text { others }(1981[\mathrm{~b}])\left(10^{8} \mathrm{~N} \mathrm{~m}^{-2}\right)\end{array}$} & $K_{1}$ & 169.43 \\
\hline & $K_{2}$ & 10.81 \\
\hline & $K_{3}$ & 109.15 \\
\hline & $K_{4}$ & 138.514897 \\
\hline & $K_{5}$ & 147.183748 \\
\hline & $K_{6}$ & 68.47 \\
\hline & $K_{7}$ & 8.19 \\
\hline
\end{tabular}

where $\beta_{1}=\left(c_{33}-c_{13}\right) / c^{2}$ and $\beta_{2}=\left(c_{11}+c_{12}-c_{13}-c_{33}\right) / c^{2}$. The small value of $\beta_{2}$ (see Table VI) implies near isotropy in the linear compressibility of ice, and further suggests that the $c / a$ ratio in ice Ih should be independent of pressure.

In monocrystalline media, Young's modulus $E$ depends on the direction of the applied stress relative to the crystal geometry. The expression for $\mathrm{E}$, for hexagonal media is

$$
E^{-1}=e_{1}+e_{2} \cos ^{2} \gamma-e_{3} \cos ^{4} \gamma
$$

where

$$
\begin{gathered}
e_{1}=\left(c_{11} c_{33}-c_{13}^{2}\right) /\left[c^{2}\left(c_{11}-c_{12}\right)\right], \\
e_{2}=\left[\left(c_{11}+c_{12}\right) c_{33}-2\left(c_{13}+c_{44}\right) c_{13}\right] /\left(c^{2} c_{44}\right)-2 e_{1}, \\
e_{3}=e_{1}+e_{2}-\left(c_{11}+c_{12}\right) / c^{2} .
\end{gathered}
$$

The values for $e_{1}, e_{2}$, and $e_{3}$, together with the coefficients $K_{i}$ as defined by equations (4) in Gammon and others (1981[b]), are also listed in Table VI.

The phase velocity for sound propagation in an arbitrary direction in ice can be determined through equations (1) $-(3)$ of Gammon and others (1981[b]), using the coefficients $K_{i}$ (Table VI) and the value for density $\rho=919.5 \mathrm{~kg} \mathrm{~m}^{-3}$. Table VII shows the velocities of acoustic modes in ice at $-16^{\circ} \mathrm{C}$ for two specific directions. 


$\begin{array}{lcc}\text { TABLE VII. SOUND VELOCITIES IN MONOCRYSTALLINE ICE, }-16^{\circ} \mathrm{C} \\ \text { Mode } & \text { Direction }(\gamma) & \text { Velocity }\left(\mathrm{m} \mathrm{s}^{-1}\right) \\ \text { Longitudinal } & 0^{\circ} & 4040.3 \\ \text { Longitudinal } & 90^{\circ} & 3892.1 \\ \text { Transverse }\left(\mathrm{T}_{1}, \mathrm{~T}_{2}\right) & 0^{\circ} & 1810.5 \\ \text { Transverse }\left(\mathrm{T}_{1}\right) & 90^{\circ} & 1929.6 \\ \text { Transverse }\left(\mathrm{T}_{2}\right) & 90^{\circ} & 1810.5\end{array}$

(b) Polycrystals

The elastic properties of homogeneous polycrystalline ice (no inclusions) are in general a complex function of the monocrystalline elastic constants, and the sizes, shapes, and orientations of the grains comprising the polycrystalline sample. However, if the grain orientations are assumed to follow a uniform random distribution and a sample includes a large number of such grains, then the bulk elastic properties should be very nearly isotropic. Furthermore, only two elastic parameters are then required to describe the bulk elastic behaviour completely. In dealing with polycrystalline ice, one of these parameters is conveniently taken to be the bulk modulus, $K$ (because of the very near isotropy in the linear compressibility), and the second can be chosen to be $\rho\left(\bar{V}_{\mathrm{L}}\right)^{2}$ where $\bar{V}_{\mathrm{L}}$ is the velocity of the longitudinal acoustic mode in polycrystalline ice. An estimate for $\bar{V}_{\mathrm{L}}$ can be obtained from monocrystal data via the integral

$$
\bar{V}_{\mathrm{L}}=\frac{1}{4 \pi} \int V_{\mathrm{L}}(\theta, \varphi) \mathrm{d} r
$$

which for cylindrical isotropy of the monocrystal reduces to

$$
\bar{V}_{L}=\int_{0}^{\pi / 2} V_{\mathrm{L}}(\gamma) \sin \gamma \mathrm{d} \gamma .
$$

Using Simpson's rule, $\bar{V}_{\mathrm{L}}$ was found to be $3844.94 \mathrm{~m} \mathrm{~s}^{-1}$ for homogeneous ice at $-16{ }^{\circ} \mathrm{C}$.

Under the stated assumption of elastic isotropy for the polycrystalline sample, the Lame constants $\lambda$ and $\mu$ (Nye, 1957; Landau and Lifshits, 1959; Malvern, 1969) can now be introduced,

$$
K=\lambda+2 \mu / 3 \quad \text { and } \quad \rho\left(\bar{V}_{\mathrm{L}}\right)^{2}=\lambda+2 \mu
$$

and further elastic parameters can be calculated. Accordingly the values for $\lambda$ and $\mu$, as well as the calculated values for shear modulus $G$, Young's modulus $E$, and Poisson's ratio $\sigma$, are given in Table VIII. The shear velocity, which for (isotropic) polycrystalline ice is given by $\bar{V}_{\mathrm{T}}=(G / \rho)^{1 / 2}$, was also calculated and found to have a value of $1956.9 \mathrm{~m} \mathrm{~s}^{-1}$.

$\begin{array}{lccc}\text { TABle VIII. } & \begin{array}{c}\text { PolyCRYSTAlline } \\ \text { ELASTIC PARAMETERS, }\end{array} & \begin{array}{c}\text { (ISOTROPIC) } \\ \text { Property }\end{array} & \begin{array}{c}{ }^{\circ} \mathrm{C} \\ \text { AVERAGED }\end{array} \\ \text { Bulk modulus } & \text { Units } & \text { Symbol } & \text { Value } \\ \text { Young's modulus } & 10^{8} \mathrm{~N} \mathrm{~m}^{-2} & K & 88.99 \\ \text { Shear modulus } & 10^{8} \mathrm{~N} \mathrm{~m}^{-2} & E & 93.32 \\ \text { Poisson's ratio } & 10^{8} \mathrm{~N} \mathrm{~m}^{-2} & G & 35.21 \\ \text { Lamé constants } & 1 & \sigma & 0.32521 \\ & 10^{8} \mathrm{~N} \mathrm{~m}^{-2} & \lambda & 65.51 \\ & 10^{8} \mathrm{~N} \mathrm{~m}^{-2} & \mu & 35.31\end{array}$


In a more general approach, the above treatment can be adapted to account for preferred grain orientations by including an appropriate statistical weighting factor $p(\gamma)$ in the integrand of Equation (6).

(c) Isothermal values

All elastic parameters quoted thus far are dynamic or adiabatic values. These are invariably yielded when acoustic measurement techniques are used. In situations where stress is applied gradually, static or isothermal elastic parameters are, in principle, appropriate. The following equation links the adiabatic and isothermal elastic compliances of an arbitrary monocrystalline medium:

$$
s_{i j k l}^{(\mathrm{T})}=s_{i j k l}^{(\mathrm{S})}+\alpha_{i j} \alpha_{k l} \mathrm{~T} /\left(\rho C_{p}\right) .
$$

Here $s^{(\mathrm{T})}$ denotes the isothermal elastic compliance tensor, $s^{(\mathrm{S})}$ the adiabatic elastic compliance tensor, $\alpha$ the thermal expansion tensor, $T$ the absolute temperature, $\rho$ the density, and $C_{p}$ the heat capacity per unit mass at constant stress. Based on the data of Butkovich (1959), the thermal expansion tensor for ice at $-16^{\circ} \mathrm{C}$ was assumed to be isotropic and was taken to be $\alpha_{i j}=50.83 \times 10^{-6} \delta_{i j}$ (the Kronecker delta). Measurements of the heat capacity of ice by Giauque and Stout (1936) have been tabulated by Dorsey (1940) and indicate a value for $C_{p}$ of $1985.4 \mathrm{~J}(\mathrm{~kg} \mathrm{deg})^{-1}$ at $-16^{\circ} \mathrm{C}$. Accordingly, the isothermal elastic moduli of ice at $-16^{\circ} \mathrm{C}$ were determined to be:

$$
\left.\begin{array}{l}
c_{11}^{(\mathrm{T})}=136.75 \\
c_{12}^{(\mathrm{T})}=68.28 \\
c_{13}^{(\mathrm{T})}=55.14 \\
c_{33}^{(\mathrm{T})}=147.61 \\
c_{44}^{(\mathrm{T})}=30.14
\end{array}\right\} \times 10^{8} \mathrm{~N} \mathrm{~m}^{-2} .
$$

These yield an isothermal bulk modulus $K^{(\mathrm{T})}=86.47 \times 10^{8} \mathrm{~N} \mathrm{~m}^{-2}$. The bulk modulus is most amenable to precise measurement by static techniques since non-elastic deformation of a monocrystalline pure sample will not result from moderate changes in applied hydrostatic pressure.

(d) Temperature corrections

The temperature dependence of the elastic constants was not specifically measured in the present work. However, the present results may be corrected to correspond to various temperatures using the data of Dantl (1969). He measured the elastic moduli of pure monocrystalline artificial ice at a large number of temperatures over the range $-0.7^{\circ} \mathrm{C}$ to $-140^{\circ} \mathrm{C}$. For the range of temperatures normally encountered in the natural environment Dantl's corrections can be considerably simplified without a significant loss of accuracy. This simplification results from neglecting quadratic terms and assuming that all elastic parameters vary according to a common linear equation as follows

$$
X(T)=X\left(T_{\mathrm{m}}\right)[1-a T] /\left[1-a T_{\mathrm{m}}\right] .
$$

Here $X$ denotes an arbitary elastic parameter (with units of pressure), $T$ denotes the temperature in ${ }^{\circ} \mathrm{C}$ and $T_{\mathrm{m}}$ denotes the temperature at which a measured value for the parameter $X$ exists. The Brillouin measurements at $-16^{\circ} \mathrm{C}$ and at $-3{ }^{\circ} \mathrm{C}$ (Gammon and others, 1980) yield $a=1.418 \times 10^{-3} \mathrm{deg}^{-1}$, while Dantl's data (at the same two temperatures) yield 
$a=1.427 \times 10^{-3} \mathrm{deg}^{-1}$. Analogously, and based on the Brillouin data at $-16^{\circ} \mathrm{C}$ and $-3{ }^{\circ} \mathrm{C}$, the linear temperature correction equation for acoustic velocity was found to be:

$$
V(T)=V\left(T_{\mathrm{m}}\right)[1-b T] /\left[1-b T_{\mathrm{m}}\right]
$$

where $b=6.196 \times 10^{-4} \mathrm{deg}^{-1}$.

\section{Comparison with other work}

Comparison with previous work (see Table IV) suggests that the present results possess the smallest overall uncertainty. This is in part due to the large volume of data (a total of 189 measurements of sound velocity) obtained at two closely spaced temperatures. As well, the quasi-random distribution of the data over the values of the angle $\gamma$ leads to comparable uncertainties in all five elastic constants. This contrasts with the results of conventional acoustic experiments where measurements at a small number of specially chosen orientations yield wide variations in the accuracy with which the five elastic constants are determined. In particular, these experiments tend to yield good values only for $c_{11}, c_{33}, c_{44}$ (and $c_{66}$ ) since they can be measured directly.

Although the sources of systematic error in the Brillouin measurements are readily identified (as above), the possible importance of such errors in acoustic velocities and elastic constants determined by other techniques is not readily assessed. Nevertheless, in comparing the various sets of elastic moduli in Table IV it is important to establish some criterion for identifying possible systematic error associated with these different sets. The parameter $2 \rho(\bar{V})^{2}$ has been chosen for this purpose. The value of $2 \rho(\bar{V})^{2}$ was determined directly for each set of elastic constants (Table IV) by calculating the square of the mean of the three acoustic velocities averaged uniformly over $\gamma$ (Gammon, unpublished [b]). Because of (i) the absence of the factor $\sin \gamma$ in this calculation, (in contrast to the polycrystalline average), to account for the nonrandom crystal orientations used by the various authors, (ii) the strong dependence on $c_{11}, c_{33}$, $c_{44}$ (and $c_{66}$ ), and, (iii) the weak dependence on the less accurately determined $c_{13}$ and $c_{12}, 2 \rho(\bar{V})^{2}$ is a sensitive and reliable indicator of the overall trend in the five elastic constants, whether measured by Brillouin spectroscopy or by ultrasonic techniques (utilizing non-random crystal orientations). From Table IV it is apparent that the variations of $2 \rho(\bar{V})^{2}$ are very small for each of the four sets of elastic constants determined by Brillouin spectroscopy. These variations are, in particular, considerably smaller than the uncertainties typically quoted in the individual elastic constants.

A preliminary inspection of Table IV reveals that the general agreement of the present results with those of previous authors is fairly good. The only obvious discrepancies are found with respect to the $c_{44}$ value as determined by Jona and Scherrer (1952) and the full set of elastic moduli as determined by Dantl (1969). The agreement among values of $2 \rho(\bar{V})^{2}$ is good for all sets of measurements except those of Dantl (1969).

Because the results of Dantl have been widely accepted as standard values for the elastic moduli of ice, their comparison with other measurements bears special significance. While difference between the average sound velocities measured by Dantl (1968, 1969, unpublished) and those measured in the present instance (and by other previous authors) may be real, the possibility of an unnoticed systematic error must not be neglected. Error in the absolute determination of acoustic velocity by pulse-echo techniques (as were employed by Dantl) is known to result from several effects. These include diffraction within the sample (Lord, 1966), 
phase changes at the point of reflection and at the point of coupling to the transducer, multiple reflection and consequent pulse-shape changes within the transducer or coupling device, as well as a variety of other effects stemming from the inherent acoustic complexity of the layered transducer-coupling-sample system (Williams and Lamb, 1958; McSkimin, 1961). In this connection, a survey of the variations in nine acoustic velocity measurements from one sample was carried out by Einsprach and Truell (1962). A single sample of carefully prepared fused silica was circulated among nine laboratories, each of which measured the transit time for longitudinal vibrations at $10 \mathrm{MHz}$. It was found that the standard deviation in the measurements of the $0{ }^{\circ} \mathrm{C}$ reference temperature was $\pm 0.5 \%$, and this corresponded to an uncertainty of at least $\pm 1 \%$ in determination of elastic modulus. (Possibly significant errors in measurement of the density or length of the sample would lead to larger uncertainty in modulus determination but these errors are neglected here.) The maximum variation in transit time measurement was $1.4 \%$ ( $2.8 \%$ in modulus determination), with the largest deviations being associated with values lying above the mean. Thus, the authors (Einspruch and Truell, 1962) note that "errors in measurement tend to produce results in velocity measurements which are too low." Finally, it should be noted that uncertainties quoted in association with the various measurements were not, in general, sufficient to account for the observed scatter, particularly in the case of those measurements lying furthest from the mean. This emphasizes the difficulty in accurately assessing the absolute uncertainty in ultrasonic measurements.

The uncertainties in the elastic moduli quoted by Dantl (1968, 1969, unpublished) were determined from the root-mean-square deviations of a large number (greater than 35) of individual determinations of the moduli at different temperatures. Apparently, no allowance was made for possible systematic error, this being assumed negligible. However, in connection with the application of the pulse-echo method, Dantl (1969) notes that "variations of pulse shape due to multiple reflections cause relatively large errors in the determination of the absolute value of the moduli." A double pulse interference (pulse superposition) method was therefore used by Dantl (unpublished) to check the absolute values of the moduli, $c_{11}, c_{33}$, and $c_{44}$. The checks showed no detectable error in the initial determination of $c_{33}$ and $c_{44}$, while $c_{11}$ was found to be $1.16 \%$ low in the initial determination. This discrepancy was neglected and the final values for the moduli were taken to be those determined by the pulse-echo method. As shown by a careful analysis of Williams and Lamb (1958), because the phase shift at the transducer-sample interface varies with applied frequency, the pulse-superposition method requires varying the applied frequency over a range determined by the acoustic transit time in the sample. With the apparatus used by Dantl (unpublished), this range corresponded to approximately the resonance halfwidth of the transducer. It was thus necessary to utilize applied frequencies deviating substantially from resonance. In brief, the error analysis carried out by Dantl leads to negligible error only under near-ideal experimental conditions. It does not specifically address the problem of estimating error under non-ideal or uncertain experimental conditions and hence tends to yield a lower limit for the measurement error. All factors being considered, it is not possible to assess the validity of his error analysis or his assumption of negligible uncertainty in velocities measured by the double pulse interference technique. Hence it does not appear to be fruitful to attempt to verify or discount the hypothesis of sample-to-sample variations in the elastic moduli of ice by comparison of the present results with those of Dantl (1968, 1969, unpublished).

The possibility of systematic error in Dantl's measurements cannot be ruled out as an explanation for the fact that his value of $2 \rho(\bar{V})^{2}$ is significantly lower than that in any other set of data in Table IV. Indeed this seems to be a particularly appropriate explanation in view of the 
further observation that, from the standpoint of internal consistency, the present Brillouin results are in best agreement with those of Dantl. Thus it appears that the unsystematic error components are comparable for these two sets of results. In any future investigation of the relative importance of systematic errors associated with the two different techniques it should therefore be sufficient to concentrate on a single, conveniently chosen, elastic parameter.

The data from Table IV show small or insignificant acoustic dispersion in ice over frequencies ranging from $5 \mathrm{kHz}$ to $10 \mathrm{GHz}$, since, as noted previously, the average of the values of $2 \rho(\bar{V})^{2}$ obtained from ultrasonic measurements agrees well with the corresponding average from the present hypersonic measurements. Thus, it appears appropriate to look for possible dispersion in the relative values of the moduli. While the scatter in the measurements makes comparisons uncertain, the ultrasonic value for $c_{11}$ does tend to be slightly less than the corresponding value determined by Brillouin spectroscopy. The converse is true for $c_{44}$.

Comparison of the present results with the temperature-corrected results of Proctor (1966) shows surprisingly good agreement in view of the large difference in the temperatures of measurement. The temperature corrections were made using the data of Proctor (1966) and the data of Dantl (1969). Barring coincidental compensation of errors, the following two conclusions can be drawn from the good agreement of the present results with those of Proctor (1966). First, there is small or negligible systematic discrepancy between the present results and those of Proctor. In this respect it is important to note that the ultrasonic apparatus of Proctor was tested on several specially prepared samples of aluminium so as to verify accuracy of the method. Quoted uncertainties in the results ranged from $0.04 \%$ for $c_{11}$ to $1.2 \%$ for $c_{12}$. Second, existing data on temperature dependence appears to be reliable over the range $-213^{\circ} \mathrm{C}$ to $-0.7^{\circ} \mathrm{C}$ (combination of results of Proctor and of Dantl).

Figure 8 shows curves of velocity versus $\gamma$ specified by the present data and by the data of Jona and Scherrer and of Dantl. The systematic difference between the present results and those of Dantl is clearly evident in Figure 8 as, also, is the disagreement between the value of $\mathrm{c}_{44}$ as measured by Jona and Scherrer (1952) and that determined from the present data.

The present values determined for the elastic moduli of ice can be used to test the results of the simplifying assumptions of Penny (1948) regarding ice structure and intermolecular forces. These assumptions led to three equations among the five elastic moduli thus facilitating calculation of all five elastic moduli from two experimentally determined elastic parameters.

The agreement of the present results with the equations of Penny (1948) is fairly good in

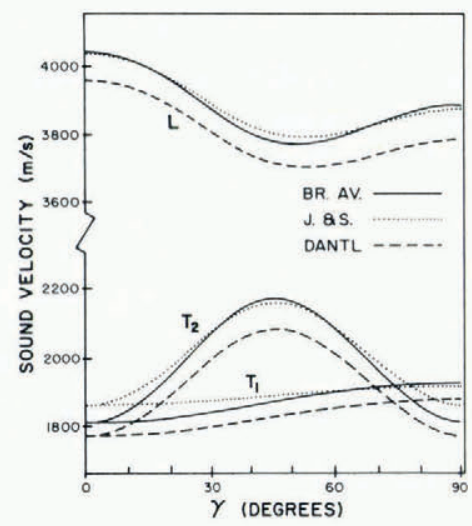

Fig. 8. Comparative plots of sound velocity versus $\gamma$ in ice. $B R$. AV.-weighted mean elastic constants from present measurements; J. \& S.-elastic constants measured by Jona and Scherrer (1952); DANTL - elastic constants measured by Dantl (1969). 
absolute terms, although not within experimental uncertainty. The fact that the first of Penny's equations is satisfied by the present results to within $1 \%$ is of particular significance since this equation effectively requires that the compressibility of ice be isotropic. Thus it in turn relates to the restriction that the four nearest neighbours of an oxygen atom in the ice crystal structure lie at the vertices of a regular tetrahedron, giving rise to a constant $c / a$ ratio of $(8 / 3)^{1 / 2}$.

The present results can be further compared with the theoretical results of Penny (1948) by calculating elastic constants from the present data subject to Penny's constraints. This procedure appears more appropriate than simple comparison with the elastic constants quoted by Penny since these elastic constants were based in part on experimental data differing significantly from the present measurements. In particular the theoretical calculations were based on the dynamic measurements of Young's modulus and Poisson's ratio in quasi-isotropic polycrystalline ice, as quoted by Northwood (1947). These values $\left(98 \times 10^{8} \mathrm{~N} \mathrm{~m}^{-2}\right.$ and 0.335 , respectively) differ from those quoted in Table VIII, possibly as a result of preferred grain orientation in the polycrystalline samples. The values from Table VIII were thus used in calculating elastic constants analogous to those calculated by Penny (1948) so as to eliminate the effects of experimental error in comparisons with the present results. Accordingly, the atomic force constants $\alpha$ and $\beta$ (Penny, 1948) were found to have values $\alpha=0.78227 \mathrm{~N} \mathrm{~m}^{-1}$, $\beta=9.0289 \mathrm{~N} \mathrm{~m}^{-1}$, yielding the following values for elastic constants which satisfy Penny's equations: $c_{11}=138.57, c_{12}=68.83, c_{13}=59.55, c_{33}=147.85, c_{44}=31.08$ (units of $10^{8} \mathrm{~N} \mathrm{~m}^{-2}$ ). It is hoped that the present measurements of elastic moduli will assist in the ongoing theoretical analysis of the molecular processes underlying the complex mechanical properties of ice.

In conclusion, it has been demonstrated that the technique of Brillouin spectroscopy is effective for determining the "local" elastic properties of ice. By using this technique it was found that the local elastic constants of ice formed under very different conditions are basically the same. Consequently, the hypothesis of sample-to-sample variation (in particular, the correlation with sample age as suggested by Dantl (1969)) has not been substantiated. Finally, it is believed that the elastic constants obtained in the present work are subject to smaller overall uncertainty than values measured previously. Given the range of samples studied, it is consequently felt that the present results are the most reliable obtained to date for use in scientific or engineering applications involving either artificial ice samples, or ice formed in the natural environment.

\section{ACKNOWLEDGEMENTS}

The authors are very grateful to Dr S. F. Ackley and Dr G. Lemieux, at the U. S. Army Cold Regions Research and Engineering Laboratory, Hanover, New Hampshire, for providing samples of Mendenhall glacier ice and Antarctic sea ice (as described in the text).

MS. received 29 March 1982

\section{REFERENCES}

Bass, R., and others. 1957. Die elastischen Konstanten des Eises, [by] R. Bass, D. Rossberg, G. Ziegler. Zeitschrit für Physik, Bd. 149, Ht. 2, p. 199-203.

Benedek, G. B., and Fritsch, K. 1966. Brillouin scattering in cubic crystals. Physical Review, Vol. 149, No. 2, p. $647-62$. 
Bogorodskiy, V. V. 1964. Uprugiye moduli kristalla l'da [Elastic moduli of ice crystals]. Akusticheskiy Zhurnal, Tom 10, No. 2, p. 152-55. [Translation in Soviet Physics-Acoustics, Vol. 10, No. 2. 1964, p. 124-26.]

Brockamp, B., and Querfurth, H. [1965.] Untersuchungen über die Elastizitätskonstanten von See- und Kunsteis. Polarforschung, Bd. 5, Jahrg. 34, Ht. 1-2. 1964, p. 253-62.

Butkovich, T. R. 1955. Density of single crystals of ice from a temperate glacier. Journal of Glaciology, Vol. 2, No. 18 , p. 553-59.

Butkovich, T. R. 1959. Thermal expansion of ice. Journal of Applied Physics, Vol. 30, No. 3, p. 350-53.

Camp, P. R. 1978. Dimensional changes of ice Ih with time. Journal of Glaciology, Vol. 21, No. 85, p. 703. [Abstract.]

Cullity, B. D. 1956. Elements of X-ray diffraction, Reading, Mass., Addison-Wesley Publishing Co., Inc. (AddisonWesley Metallurgy Series.)

Dantl, G. 1968. Die elastischen Moduln von Eis-Einkristallen. Physik der kondensierten Materie, Bd. 7, Ht. 5, p. 390-97.

Dantl, G. 1969. Elastic moduli of ice. (In Riehl, N., and others, ed. Physics of ice: proceedings of the international symposium on physics of ice, Munich, Germany, September 9-14, 1968. Edited by N. Riehl, B. Bullemer, H. Engelhardt New York, Plenum Press, p. 223-30.)

Dantl. G. Unpublished. Elastische Moduln und mechanische Dämpfung in Eis-Einkristallen. [Ph.D. thesis, Technische Hochschule Stuttgart, 1967.]

Dantl, G., and Gregora, I. 1968. Dichte in hexagonalem Eis. Naturwissenschaften, Bd. 55, Ht. 4, p. 176.

Dorsey, N. E. 1940. Properties of ordinary water-substance in all its phases: water-vapor, water, and all the ices. New York, Reinhold Publishing Corporation. (American Chemical Society. Monograph Series, No. 81.)

Durand, G. E., and Pine, A. S. 1968. High-resolution low-level Brillouin spectroscopy in solids. IEEE Journal of Quantum Electronics, Vol. QE-4, No. 9, p. 523-28.

Einspruch, N. G., and Truell, R. 1962. Results of an ultrasonic measurement survey. Journal of Applied Physics, Vol. 33, No. 10, p. 3087-88.

Fletcher, N. H. 1970. The chemical physics of ice. Cambridge, Cambridge University Press. (Cambridge Monographs on Physics.)

Gammon, P. H. Unpublished [a]. Determination of the elastic constants of beta-carbon monoxide by Brillouin spectroscopy. [M.Sc. thesis, Memorial University of Newfoundland, 1978.]

Gammon, P. H. Unpublished [b]. Brillouin spectroscopic studies of the elastic properties of artificial and natural ice samples. [Ph.D. thesis, Memorial University of Newfoundland, 1981.]

Gammon, P. H., and others. 1978. Brillouin scattering in single crystals of $\beta$-carbon monoxide: determination of the elastic constants at the triple point, by P. H. Gammon, H. Kiefte, and M. J. Clouter. Journal of Chemical Physics, Vol. 70, No. 2, p. 810-15.

Gammon, P. H., and others. 1980. Elastic constants of ice by Brillouin spectroscopy, by P. H. Gammon, H. Kiefte, and M. J. Clouter. Journal of Glaciology, Vol. 25, No. 91, p. 159-67.

Gammon, P. H., and others. 1981[a]. Brillouin spectroscopic studies of a crystal grain boundary region in ice Ih, by P. H. Gammon, H. Kiefte, M. J. Clouter, and W. W. Denner. Solid State Communications, Vol. 37, No. 4, p. $313-17$.

Gammon, P. H., and others. 1981[b]. Note on analysis of acoustic data from hexagonal monocrystals of unknown orientation, [by] P. H. Gammon, H. Kiefte, M. J. Clouter, and W. W. Denner. Journal of the Acoustical Society of America, Vol. 69, No. 5, p. 1503-04. [Letter.]

Giauque, W. F., and Stout, J. W. 1936. The entropy of water and the third law of thermodynamics. The heat capacity of ice from $15^{\circ}$ to $273^{\circ} \mathrm{K}$. Journal of the American Chemical Society, Vol. 58, No. 7, p. 1144-50.

Ginnings, D. C., and Corruccini, R. J. 1947. An improved ice calorimeter - the determination of its calibration factor and the density of ice at $0^{\circ} \mathrm{C}$. Journal of Research of the National Bureau of Standards, Vol. 38, No. 6, Research Paper RP1796, p. 583-91.

Glen, J. W. 1974. The physics of ice. Hanover, N. H., U.S. Cold Regions Research and Engineering Laboratory. (Cold Regions Science and Engineering Monograph II-C2a.)

Green, R. E., jr, and Mackinnon, L. 1956. Determination of the elastic constants of ice single crystals by an ultrasonic pulse method. Journal of the Acoustical Society of America, Vol. 28, No. 6, p. 1292.

Higashi, A. 1969. Mechanical properties of ice single crystals. (In Riehl, N., and others, ed. Physics of ice: proceedings of the international symposium on physics of ice, Munich, Germany, September 9-14, 1968. Edited by N. Riehl, B. Bullemer, H. Engelhardt. New York, Plenum Press, p. 197-212.)

Hobbs, P. V. 1974. Ice physics. Oxford, Clarendon Press. 
Jackson, J. D. 1975. Classical electrodynamics. Second edition. New York, John Wiley and Sons, Inc.

Jona, F., and Scherrer, P. 1952. Die elastischen Konstanten von Eis-Einkristallen. Helvetica Physica Acta, Vol. 25, Fasc. 1-2, p. 35-54.

Kamb, W. B. 1973. Crystallography of ice. (In Whalley, E., and others, ed. Physics and chemistry of ice: papers presented at the Symposium on the Physics and Chemistry of Ice, held in Ottawa, Canada, 14-18 August 1972. Edited by E. Whalley, S. J. Jones, L. W. Gold. Ottawa, Royal Society of Canada, p. 28-41.)

Landau, L. D., and Lifshits, Ye. M. 1959. Theory of elasticity. Translated from the Russian by J. B. Sykes and W. H. Reid. London, Pergamon Press. (Course of Theoretical Physics, Vol. 7.)

Lord, A. E. 1966. Changes in velocity of an elastic pulse owing to geometrical diffraction. Journal of the Acoustical Society of America, Vol. 40, No. 1, p. 163-69.

McSkimin, H. J. 1961. Pulse superposition method for measuring ultrasonic wave velocities in solids. Journal of the Acoustical Society of America, Vol. 33, No. 1, p. 12-16.

Maeno, N. 1973. Measurements of surface and volume conductivities of single ice crystals. (in Whalley, E., and others, ed. Physics and chemsitry of ice: papers presented at the Symposium on the Physics and Chemistry of Ice, held in Ottawa, Canada, 14-18 August 1972. Edited by E. Whalley, S. J. Jones, L. W. Gold, Ottawa, Royal Society of Canada, p. 140-43.)

Malvern, L. E. 1969. Introduction to the mechanics of a continuous medium. Englewood Cliffs, N. J., Prentice-Hall. (Prentice-Hall Series in Engineering of the Physical Sciences.)

Musgrave, M. J. P. 1970. Crystal acoustics. San Francisco, Holden-Day.

Northwood, T. D. 1947. Sonic determination of the elastic properties of ice. Canadian Journal of Research. Sect. A, Vol. 25, No. 1, p. 88-95.

Nye, J. F. 1957. Physical properties of crystals. Oxford, Clarendon Press.

Penny, A. H. A. 1948. A theoretical determination of the elastic constants of ice. Proceedings of the Cambridge Philosophical Society, Vol. 44, Pt. 3, p. 423-39.

Proctor, T. M., jr. 1966. Low-temperature speed of sound in single-crystal ice. Journal of the Acoustical Society of America, Vol. 39, No. 5, Pt. 1, p. 972-77.

Sandercock, J. R. 1975. Some recent developments in Brillouin scattering. RCA Review, Vol. 36, No. 1, p. 89-107.

Schwarz, J., and Weeks, W. F. 1977. Engineering properties of sea ice. Journal of Glaciology, Vol. 19, No. 81, p. 499-531.

Stoicheff, B. P. 1973. Brillouin and Raman spectroscopy with lasers. (In Feld, M. S., and others, ed. Fundamental and applied laser physics. Proceedings of the Esfahan symposium, August 29 to September 5, 1971. Edited by M. S. Feld, A. Javan, and N. A. Kurnit. New York, John Wiley and Sons, Inc., p. 573-611.)

Stoicheff, B. P. 1977. Brillouin spectroscopy and elastic constants. (In Klein, M. L., and Venables, J. A., ed. Rare gas solids. Vol. 2 New York, Academic Press, p. 979-1020.)

Teichmann, I., and Schmidt, G. 1965. Untersuchungen über den reziproken Piezoeffekt des Eises. Physica Status Solidi, Vol. 8, No. 3, p. K145-47.

Voigt, W. 1910. Lehrbuch der Kristallphysik. Leipzig, Teubner.

Weeks, W. F., and Assur, A. 1967. The mechanical properties of sea ice. U. S. Cold Regions Research and Engineering Laboratory. Cold regions science and engineering. Hanover, N. H., Pt. II, Sect. C3.

Whalley, E. 1969. Structure problems of ice. (In Riehl, N., and others, ed. Physics of ice: proceedings of the international symposium on physics of ice, Munich, Germany, September 9-14, 1968. Edited by N. Riehl, B. Bullemer, H. Engelhardt. New York, Plenum Press. p. 19-43.)

Williams, J., and Lamb, J. 1958. On the measurement of ultrasonic velocity in solids. Journal of the Acoustical Society of America, Vol. 30, No. 4, p. 308-13.

Zarembovitch, A., and Kahane, A. 1964. Détermination des vitesses de propagation d'ondes ultrasonores longitudinales dans la glace. Étude de leur variation avec la température. Comptes Rendus Hebdomadaires des Séances de l'Academie des Sciences (Paris), Tom. 258, No. 9, p. 2529-32. 